\title{
Prebiotic Chemistry: What We Know, What We Don't
}

\section{H. James Cleaves II}

Published online: 27 September 2012

(C) Springer Science+Business Media, LLC 2012

\begin{abstract}
How life on Earth began remains an unexplained scientific problem. This problem is nuanced in its practical details and the way attempted explanations feedback with questions and developments in other areas of science, including astronomy, biology, and planetary science. Prebiotic chemistry attempts to address this issue theoretically, experimentally, and observationally. The ease of formation of bioorganic compounds under plausible prebiotic conditions suggests that these molecules were present in the primitive terrestrial environment. In addition to synthesis in the Earth's primordial atmosphere and oceans, it is likely that the infall of comets, meteorites, and interplanetary dust particles, as well as submarine hydrothermal vent synthesis, may have contributed to prebiotic organic evolution. The primordial organic soup may have been quite complex, but it did not likely include all of the compounds found in modern organisms. Regardless of their origin, organic compounds would need to be concentrated and complexified by environmental mechanisms. While this review is by no means exhaustive, many of the issues central to the state of the art of prebiotic chemistry are reviewed here.
\end{abstract}

Keywords Prebiotic chemistry · Origin of life · Organic chemistry $\cdot$ Biomolecules

\section{Introduction}

"Prebiotic chemistry" can be understood to mean various things: chemistry which occurred before life began or the chemistry which led to life on Earth, and possibly on other

H. J. Cleaves II $(\square)$

Blue Marble Space Institute of Science,

Washington, DC 20016, USA

e-mail: hcleaves@bmsis.org planets. Workers in the field practically define it as naturally occurring, mainly organic, chemistry in planetary or other solar system environments, which may have contributed to the origin of life on Earth, or elsewhere. The terms "abiotic chemistry" (chemistry which takes place in the absence of biology) and "prebiotic chemistry" are in some senses synonymous. Since it is generally assumed that the universe is not goal directed, and since it is not known what processes led to the origin of life, the study of prebiotic chemistry almost certainly includes both productive and nonproductive chemical processes. This review places this chemistry in a historical and cosmic context and details some of the known reactions thought to be important. However, the interested reader is referred to more technical texts (Miller and Orgel 1974; Cleaves 2008; Cleaves and Lazcano 2009) and references therein.

The origin of life remains unexplained despite decades (or perhaps centuries, depending on where one historically marks the starting point) of research. A considerable amount of study has provided compelling details as to how it might have occurred and whether it is likely to be a universal phenomenon. The development of modern thought on the topic has a long and winding history and has been modified to adapt to developments in other fields, including astronomy, biology, chemistry, and geology. This review covers the synthesis of small organic compounds; however, it should be borne in mind that the major uncertainties revolve around how these compounds self-organize into self-replicating systems.

Birth of a Model

At the beginning of the twentieth century, several less-thanmainstream scientists believed they were able to demonstrate spontaneous generation (Hanczyc 2008). The majority of scientists viewed their experiments with skepticism, partly 
due to Pasteur's masterful negative demonstration in the nineteenth century (Fry 2000). This left a paradox: life appeared to have a common ancestor, yet the origin of life could not be reproduced experimentally. Various explanations for this paradox were presented; for example Svante Arrhenius proposed that, while it was then known that the Earth was not infinitely old, the universe might be, and it was thus possible that, like the universe, life was infinitely old. The spores of some type of bacterium-like seed organism might constantly inoculate new planets with life, which was then able to evolve into the higher forms observed today (Fry 2000).

An alternative and more experimentally addressable proposal was put forth almost simultaneously by Oparin (1924) and Haldane (1929), suggesting that the early Earth may have been markedly different, providing chemical conditions facilitating spontaneous generation. Especially important were Oparin's suggestions that organic compounds, presumably required for the origin of the first organisms, could have been delivered to the Earth on meteorites or that they may have been generated in the early atmosphere, had it been reducing.

In the 1950s, Nobel prize-winning American chemist Harold Urey proposed that the early atmosphere would have been largely reducing, based on the preponderance of hydrogen in the solar system (Urey 1952). Chemists use the terms "oxidizing" and "reducing" to describe the elements that carbon typically bonds with in an atmosphere. Carbon can form four bonds with other atoms: an oxidizing atmosphere, carbon is bound via two double bonds with $\mathrm{O}$ to give $\mathrm{CO}_{2}$ (an oxidized form of carbon) or, in a reducing atmosphere, with four $\mathrm{H}$ atoms to give $\mathrm{CH}_{4}$ (a reduced form of carbon). The import of this is that it is considerably easier to make organic compounds abiotically from reduced gases than from oxidized ones (see below).

A young graduate student, Stanley Miller, after attending a lecture by Urey on his ideas, suggested to Urey trying an experiment to test this model as a thesis project. The experiment itself was simple: a flask filled with reduced gases and heated circulating water (simulating the Earth's hydrologic cycle) was subjected to an electrical discharge, simulating lightning (Fig. 1).

Chemical analysis of the resulting products revealed a surprisingly efficient synthesis of a number of amino acids found in biochemistry, including glycine, and racemic alanine and aspartic acid (Miller 1953). While there had been earlier laboratory demonstrations of organic synthesis using electric discharges (see, for example, Löb 1913), this experiment is generally considered the first conducted in the context of trying to understand the origin of life. It is thus widely deemed to have opened the modern experimental period of research into the mechanism of the origin of life and to have been the first intentional example of "prebiotic chemistry."

Coincidentally, Watson and Crick published their structure for the DNA double helix within a week of the publication of Miller's results (Watson and Crick 1953). Until that time, it had been widely debated whether proteins or nucleic acids were the carriers of genetic inheritance (though the evidence was strongly in favor of the latter): the structure of DNA left little doubt. This close historical juxtaposition of discoveries reveals a common motif in prebiotic chemistry and in originsof-life models in general: discoveries in other fields frequently drive advances in origin of life models.

All modern organisms are composed of cells, a fact recognized since the 1800s. However, the understanding of the molecular-scale functioning of cells has undergone remarkable development, allowing more precise questions to be posed regarding the origin of the first living cell.

Modern cells share a variety of common biochemical characteristics which are believed to be evidence of a common ancestry: all are bounded by lipid membranes, all contain DNA, all contain ribosomes, and all use a very similar genetic code to produce the protein enzymes that carry out cellular metabolism.
Fig. 1 The Miller-Urey apparatus. The 500-liter flask contained heated water, evaporating upward and coming into contact with the gases contained in the five-liter flask. The molecules created by contact with the electric discharge were returned to the 500-cubic centimeter flask by the condenser. Reproduced from Lazcano and Bada (2003)
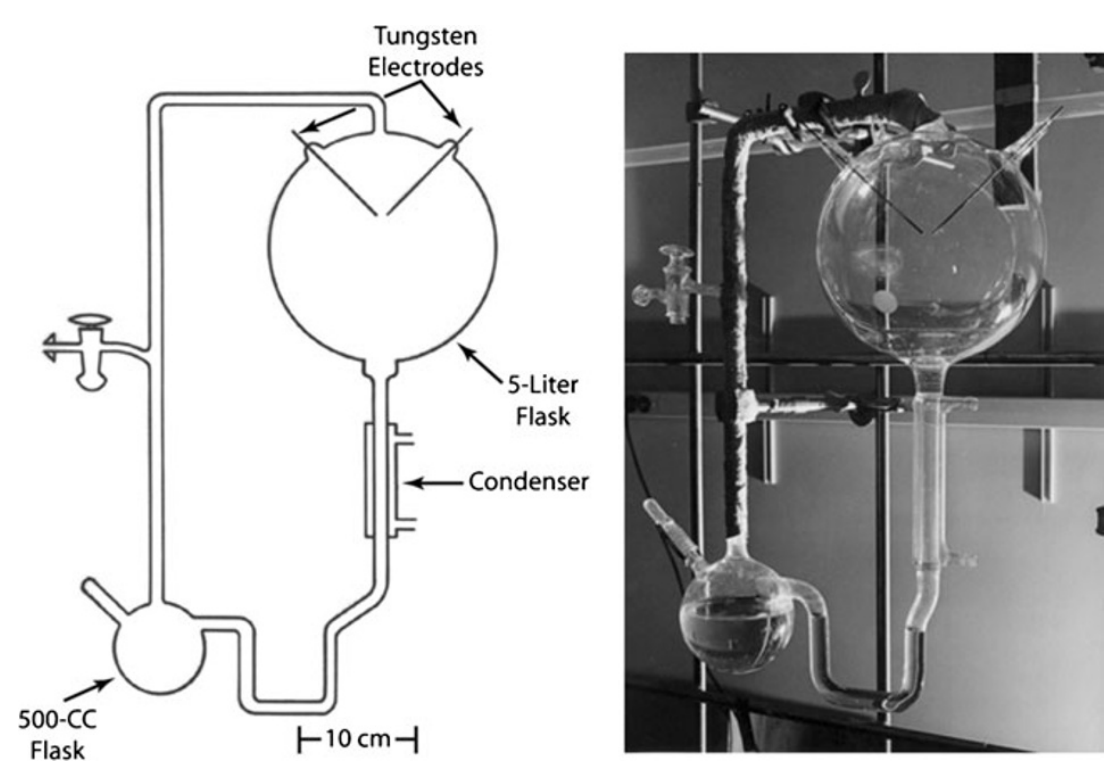


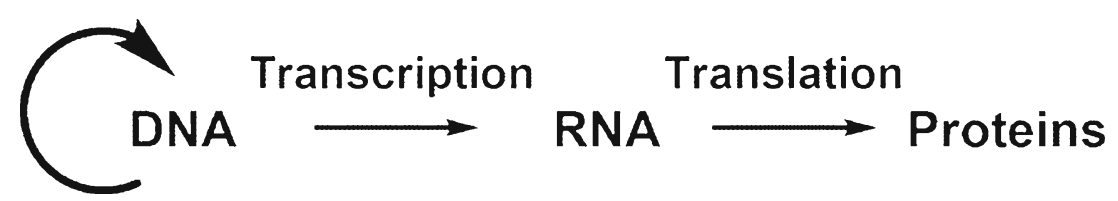

Fig. 2 The central dogma of information flow in biology. The circular arrow leading back to DNA represents the fact that DNA is a template for its own replication, a process which is mediated by protein and RNA

The general flow of information in cells is known as the "central dogma" of biology (Fig. 2), which holds that DNA encodes various RNA molecules, which in turn are used to make coded proteins. These RNA molecules include ribosomal RNA (rRNA), which folds into ribosomes (that also contain numerous structurally important peptides) - the proteinmanufacturing machines of the cell, transfer RNA (small folded RNA adapter molecules that ensure the precise amino acid coded by a DNA strand gets incorporated into the proper location in a protein) and messenger RNA (into which coded genetically encoded messages of DNA are transcribed before being translated into proteins). DNA is itself copied using various protein enzymes and small RNA primers.

The fact that proteins are needed to make DNA and DNA is needed to make proteins leads to a "chicken or egg paradox": which logically would have had to arise first? The central role of RNA in this process led some to speculate that it could be the solution to the paradox (Crick 1968; Orgel 1968; Woese 1968), and this led to the notion of an "RNA World" (Gesteland and Atkins 1993), a putative period in which RNA functioned as both catalyst and genetic molecule. Some scientists interpret the RNA World to mean that life began with a self-replicating RNA molecule, while others interpret it to mean that life passed through a period in which RNA was merely extremely important in biochemistry. The perceived simplicity of the first interpretation has driven considerable research into the prebiotic synthesis of RNA.

As recently as the 1990s, the living world was divided into five kingdoms, the animals, plants, fungi, protists, and bacteria (Whittaker 1969). Comparison of rRNA sequences (which presumably are resistant to evolutionary drift) has revised this classification scheme into three domains, phylogenetically organizable into an evolutionary tree of life (Fig. 3): the Eukarya (comprising the eukaryotes), the Bacteria, and the Archaebacteria (Woese et al. 1990). This last group has a number of unique characteristics, including specialized forms of metabolism and membrane lipids.

Some analyses of this tree suggest hyperthermophilic archaebacteria are the oldest organisms on Earth (Wang et al. 2007), which has been used to argue that the types of environments these organisms inhabit presently were the earliest environments for life and thus likely sites of the origin of life. This idea remains controversial (Arrhenius et al. 1999; Gupta 2000). The reconstructed tree suggests that the Last Universal Common Ancestor (LUCA) of all modern biology was a single-celled prokaryote, albeit one with an already sophisticated and very modern biochemistry, suggesting a prior protracted period of biochemical evolution.

To address the question of the origin of LUCA, it is necessary to examine models for how the Earth formed, what geochemical environments may have been available on the early Earth, and what types of organics could have been produced in each.

\section{History of the Earth and Solar System}

The Earth is believed to be $\sim 4.5$ billion years old, only $10-15$ million years younger than the solar system itself (Dalrymple 1994). The accepted model for the origin of the solar system is the nebular hypothesis (Montmerle et al. 2006), which holds that the solar system condensed into a disk from a presolar nebula, a cloud of gas and dust composed of remnants of a previous supernova. Due to inelastic collisions during gravitational accretion of small particles, larger bodies formed, gradually coming to occupy orbits at varying distances from the nascent central star, our Sun.

These bodies were dramatically altered in composition when the Sun accreted enough mass to trigger the ignition of thermonuclear fusion in its interior, releasing vast amounts of energetic electromagnetic radiation. Lower boiling point compounds in the surrounding disk were driven outward from the Sun, as in a distillation, each condensing beyond its relative condensation point. Thus, volatile components such as methane, water, and $\mathrm{N}_{2}$ coalesced into outer solar system bodies such as the gas and ice giant planets (Saturn, Jupiter, Neptune, and Uranus) and the Oort cloud and Kuiper belt comets, while higher boiling-point compounds such as metal oxides and silicates, which make up the bulk of the inner rocky planets, condensed nearer in.

The smaller resultant bodies, comets, meteors, and interstellar dust particles (IDPs) continue to impact the planets presently, and it is likely that this flux was higher around the time that life formed on Earth. The presence of extraterrestrial organic molecules in meteorites, comets, and IDPs is firmly established and has led to proposals that these were sources of organic compounds possibly necessary for the origin of life (Oró 1961; Anders 1989; Chyba et al. 1990; Chyba and Sagan 1992).

The flux of extraterrestrial organics to the early Earth has been estimated based on the lunar cratering record (Chyba and Sagan 1992). These may have contributed significantly to the primitive Earth's prebiotic organic inventory, even if the early Earth's atmosphere were oxidizing or neutral 
Fig. 3 The reconstructed Tree of Life based on ribosomal RNA sequences. Figure reproduced from Pace (1997)

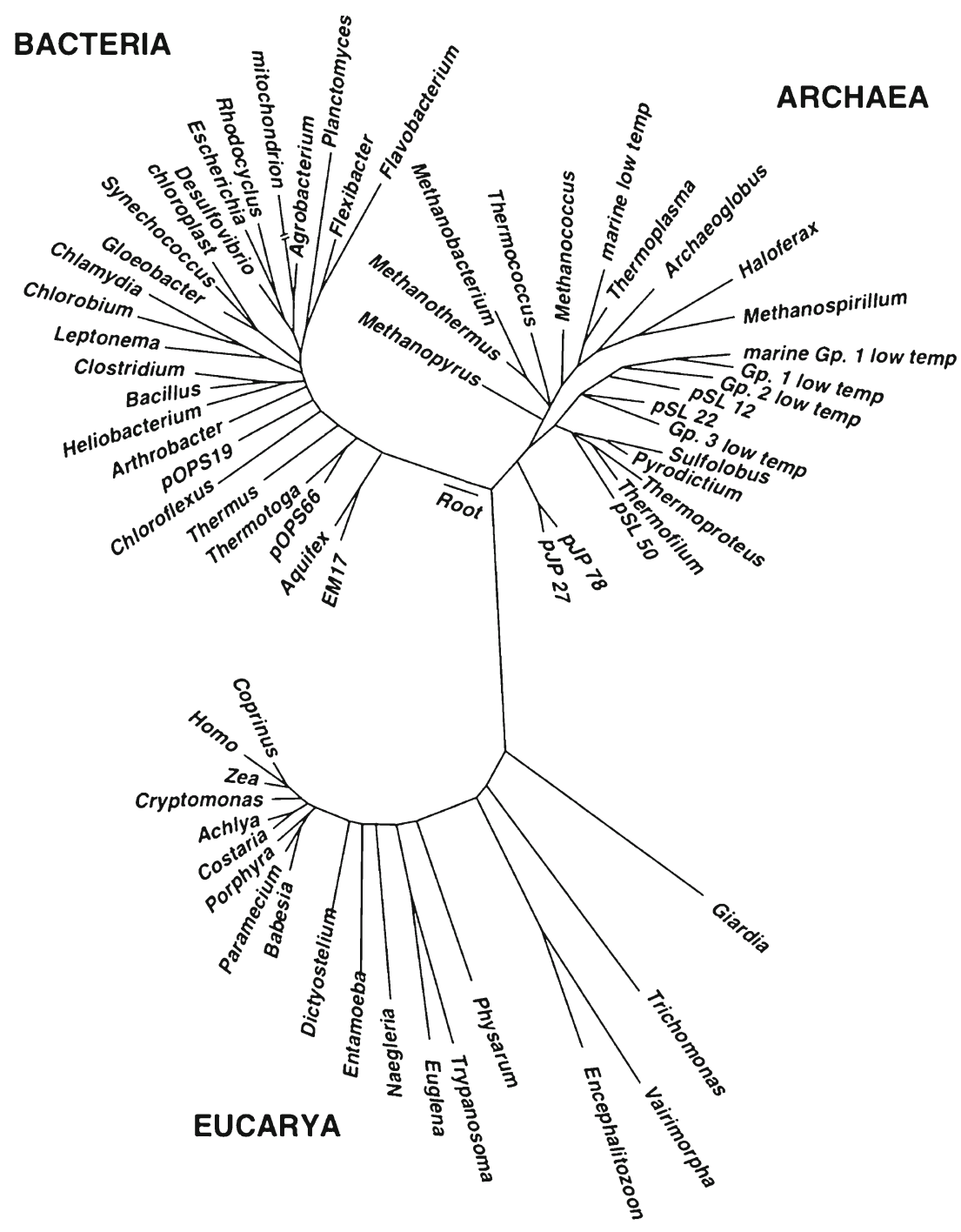

(Chyba and Sagan 1992; Thomas et al. 1996). Their components resemble the products of atmospheric synthesis under reducing conditions (Wolman et al. 1972); thus, their compositions are worth examining.

\section{Comets}

Comets are mixtures of dust and ice accreted early in the history of the solar system (Festou et al. 2004). In addition to water ice and various inorganic components, the volatile organic components of several comets have been measured spectroscopically (Ehrenfreund and Charnley 2000). Highly reactive organic compounds such as hydrogen cyanide $(\mathrm{HCN})$ and formaldehyde $(\mathrm{HCHO})$, among others, though variable from comet to comet, are often observed in high abundance (Table 1).

Measurement of the hydrogen isotope ratios of cometary water suggests that some of the Earth's oceans may be derived from comets (Chyba 1990; Meier et al. 1998). If this is true, comets could also have delivered organics, though the survival of these would depend on the nature of the delivery process (Oró 1961; Oró et al. 1980). Assuming that cometary nuclei have a one-gram per cubic centimeter density, a one-kilometer-diameter comet would

Table 1 The abundance of small molecules relative to water in comet Hale-Bopp as measured spectroscopically

Adapted from

Bockelée-Morvan et al. (2000)

\begin{tabular}{ll}
\hline Compound & Abundance \\
\hline $\mathrm{H}_{2} \mathrm{O}$ & 100 \\
$\mathrm{CO}$ & 23 \\
$\mathrm{CO}_{2}$ & 6 \\
$\mathrm{CH}_{3} \mathrm{OH}$ & 2.4 \\
$\mathrm{H}_{2} \mathrm{CO}$ & 1.1 \\
$\mathrm{NH}_{3}$ & 0.7 \\
$\mathrm{CH}_{4}$ & 0.6 \\
$\mathrm{HCN}$ & 0.25 \\
$\mathrm{HCONH}_{2}$ & 0.02 \\
$\mathrm{CH}_{3} \mathrm{CHO}$ & 0.02 \\
\hline
\end{tabular}


contain $2 \times 10^{11}$ moles of $\mathrm{HCN}$, or 40 nanomoles per square centimeter of the Earth's surface. This is comparable to the yearly production of $\mathrm{HCN}$ in a reducing atmosphere from electric discharges and would be important if the Earth did not have a reducing atmosphere, assuming complete survival of the HCN on impact.

While comets are extremely cold, it appears that some aqueous-phase organic reactions have occurred in them, as evidenced by the detection of the simplest amino acid, glycine, in particles returned from comets (Elsila et al. 2009); thus comets could have delivered some more complex compounds as well.

\section{Meteorites}

Meteorites represent generally less volatile remnants of the early solar system, i.e., objects which formed closer to the Sun and underwent more significant thermal processing (Lauretta and McSween 2006). Their compositions range from metallic to stony. The latter category includes a class with which prebiotic chemists are particularly fascinated, the carbonaceous chondrites (CCs), which contain a significant organic component, usually one to two $\%$ by mass (Alexander et al. 2007). Besides a few recovered cometary grains, CCs remain the best-studied bona fide examples of "prebiotic chemistry," represented by several hundred examplars in various curated collections around the world. $\mathrm{CC}$ organic material is variable in composition, but typically $70-99 \%$ is a complex high molecular weight kerogen-like material, with the remainder being small soluble organic compounds (Pizzarello et al. 2006).

A variety of organic compounds have been identified in $\mathrm{CCs}$, including many found in modern biochemistry (Pizzarello et al. 2006). That these compounds are indigenous to the meteorites, and not terrestrial contamination, is suggested by the facts that they have unusual isotopic ratios and include types of compounds not typically found in biochemistry; and that compounds with stereocenters are found in nearly equal quantities with respect to their optical isomers, with some notable exceptions (Pizzarello and Cronin 2000; Glavin and Dworkin 2009). A brief summary of the types and relative abundances of compounds identified to date is shown in Table 2.

\section{IDPs}

The input from IDPs may have been more important than that of comets or meteorites. Their present infall rate is large, and on the primitive Earth, it may have been greater by a factor of 100 to 1,000 (Love and Brownlee 1993). The organic composition of IDPs is poorly understood (Maurette 1998); the only molecules that have been identified to date are polycyclic aromatic hydrocarbons and $\alpha$-aminoisobutyric acid (Gibson
Table 2 Organic compounds detected in the Murchison carbonaceous chondrite

\begin{tabular}{lll}
\hline Class & $\begin{array}{l}\text { Concentration } \\
\text { (parts per million) }\end{array}$ & $\begin{array}{l}\text { Compounds } \\
\text { identified }\end{array}$ \\
\hline Aliphatic hydrocarbons & $>35$ & 140 \\
Aromatic hydrocarbons & 22 & 87 \\
Polar hydrocarbons & $<120$ & 10 \\
Carboxylic acids & $>300$ & 48 \\
Amino acids & 60 & 74 \\
Hydroxy acids & 15 & 38 \\
Dicarboxylic acids & $>30$ & 44 \\
Dicarboximides & $>50$ & 2 \\
Pyridine carboxylic acids & $>7$ & 7 \\
Sulfonic acids & 67 & 4 \\
Phosphonic acids & 2 & 4 \\
N-Heterocycles & 7 & 31 \\
Amines & 13 & 20 \\
Amides & Nd & 27 \\
Polyols & 30 & 19 \\
Imino acids & nd & 10 \\
Total & 778 & 565 \\
\hline
\end{tabular}

Adapted from (Pizzarello et al. 2006)

$n d$ not determined

1992; Clemett et al. 1993). Heterogeneous organic polymers loosely termed tholins (also produced by electric discharges, ionizing radiation, and ultraviolet light) could be major components of IDPs. Amino acids are released from tholins on acid hydrolysis (Khare et al. 1986); tholins could thus also be a source of organics. On entry to the Earth's atmosphere, IDPs could be heated and their tholins pyrolyzed, creating HCN and other molecules, which could then participate in terrestrial reactions (Mukhin et al. 1989; Chyba et al. 1990).

Formation of the Earth and the Origins of the Atmosphere and Oceans

As it is widely believed that life requires an aqueous environment, and it is a cornerstone of many ideas regarding the origins of Earth's early organics that the early atmosphere was reducing, it is worth discussing the origin of the Earth's oceans, atmosphere, and crust, as these have a complex interplay which affects their ability to produce organic compounds.

During solar system formation, as asteroids accreted, the heat generated from the radioactive decay of elements (such as ${ }^{26} \mathrm{Al}$ and ${ }^{40} \mathrm{~K}$ ) was trapped in the interiors of these bodies, which began to warm up. As asteroidal component melted and liquefied, they migrated inward or outward within these bodies depending on their densities. As asteroids accreted into planetesimal-sized objects, the internally trapped heat 
became great enough to melt rock and metal, and denser materials migrated inward to form metallic cores, as in the rocky planets.

Since much of this material was reduced iron, the migration of this metal to the Earth's core took with it a great deal of the planet's reducing equivalents. Much of the lighter material, including elements such as $\mathrm{C}, \mathrm{N}$, and $\mathrm{H}$, migrated toward the surface, with the oxidation state of these elements determined by the equilibration conditions they were exposed to during migration.

Whether the early atmosphere was ever reducing remains contentious (Tian et al. 2005), but it seems unlikely that it was for very long. An $\mathrm{N}_{2} / \mathrm{CO}_{2}$-dominated atmosphere may be the most stable state in the absence of biology. $\mathrm{O}_{2}$ in the present atmosphere is almost entirely generated from biological photosynthesis. In the absence of biology, the lifetime of $\mathrm{O}_{2}$ would be extremely short due to its reaction with elements such as iron in the crust (for example, $1.5 \mathrm{O}_{2}+2$ $\mathrm{Fe}^{2+} \rightarrow \mathrm{Fe}_{2} \mathrm{O}_{3}$ ). A consequence of the lack of $\mathrm{O}_{2}$ in the early atmosphere is that there would have also been little UVabsorbing ozone $\left(\mathrm{O}_{3}\right)$, which would have allowed highly energetic bond-breaking UV radiation to reach the Earth's surface (Cleaves and Miller 1998). It is generally believed, in addition, that the early Sun produced a far larger amount of radiation in the UV region (Kasting and Siefert 2002) than at present.

The oxidation state of the early mantle likely governed the distribution of outgassed species. Holland (1962) proposed, based on the Earth accreting homogenously and cold that the Earth's atmosphere went through two stages: an early reduced stage before differentiation of the mantle and a later neutral/oxidized stage after differentiation. During the first stage, the redox state of the mantle was governed by the $\mathrm{Fe}^{\circ} / \mathrm{Fe}^{2+}$ redox pair. The atmosphere in this stage would be composed of $\mathrm{H}_{2} \mathrm{O}, \mathrm{H}_{2}, \mathrm{CO}$, and $\mathrm{N}_{2}$, with approximately $0.27-2.7 \times 10^{-5}$ atmospheres of $\mathrm{H}_{2}$. Once $\mathrm{Fe}^{\circ}$ had segregated into the core, the redox state of magmas would have been controlled by the $\mathrm{Fe}^{2+} / \mathrm{Fe}^{3+}$ pair or fayalite-magnetite-quartz buffer.

If the core differentiated rapidly (via rapid sinking of $\mathrm{Fe}^{\circ}$ into the core), the early atmosphere may have resembled the composition of modern volcanic gases (Rubey 1951). Rubey estimated that a $\mathrm{CH}_{4}$-dominated atmosphere could not have persisted for more than $10^{5}-10^{8}$ years due to photolysis. The Urey/Oparin atmosphere $\left(\mathrm{CH}_{4}, \mathrm{NH}_{3}, \mathrm{H}_{2} \mathrm{O}\right)$ model is thus based on astrophysical and cosmochemical constraints, while Rubey's model is based on extrapolation of the geological record. Although early theoretical work had an influence on research, modern thinking on the origin and evolution of the solar system, the Earth, and its atmosphere and oceans has not been shaped largely with the origin of life in mind. Rather, current origin-of-life theories are usually modified to fit frequently-changing geochemical models.
Light atmospheric gases such as $\mathrm{H}_{2}$ would have been prone to rapid escape to space due to their low escape velocities, while others such as $\mathrm{NH}_{3}$ would be rapidly decomposed in the atmosphere by UV photolysis (Ferris and Nicodem 1972; Kuhn and Atreya 1979). Nevertheless, low levels of these compounds could have been maintained at steady state, and significant amounts of $\mathrm{NH}_{3}$ could have dissolved in the oceans if the $\mathrm{pH}$ of the early oceans was lower than the $\mathrm{p} K_{\mathrm{a}}$ of $\mathrm{NH}_{3}$ ( 9.2 at 25 degrees Celsius) (Bada and Miller 1968).

Water outgassed as steam and slowly condensed as the crust cooled, forming the Earth's surface waters. There is some evidence from zircons (weathering-resistant minerals found in crustal rocks) that liquid water was present as early as 4.4 billion years ago (Valley et al. 2002). The temperature and $\mathrm{pH}$ of the early oceans remain poorly constrained, with possible ranges between zero and 100 degrees Celsius and a pH range of 5 to 11 (Kempe and Degens 1985; Morse and Mackenzie 1998).

If a reducing atmosphere was required for terrestrial prebiotic organic synthesis, the crucial question is the source of $\mathrm{H}_{2}$. Miller and Orgel (1974) estimated the $\mathrm{pH}_{2}$ as $10^{-4}$ to $10^{-2}$ atmospheres, depending on the various sources and sinks. $\mathrm{H}_{2}$ could have been supplied to the primitive atmosphere by several sources (Tian et al. 2005), and it is unclear what would have governed this balance.

The oxidation state of the atmosphere is important for the production of $\mathrm{HCN}$, an important reactant in the prebiotic synthesis of purines and amino acids (see below). $\mathrm{In}_{\mathrm{CH}} / \mathrm{N}_{2}$ atmospheres, $\mathrm{HCN}$ is produced abundantly (Chameides and Walker 1981; Stribling and Miller 1987), but in $\mathrm{CO}_{2} / \mathrm{N}_{2}$ atmospheres, most of the $\mathrm{N}$ atoms produced by splitting $\mathrm{N}_{2}$ recombine with $\mathrm{O}$ atoms to form $\mathrm{NO}_{x}$ species (Chameides and Walker 1981). Reduced gas mixtures are generally more conducive to organic synthesis than oxidizing or neutral gas mixtures. Even mildly reducing gas mixtures produce copious amounts of organic compounds, and it seems likely that energy was the not the limiting factor (Stribling and Miller 1987).

\section{Evidence for Life on Earth}

Evidence for life on Earth was once restricted to animals leaving visible fossils, which extended back as far as the beginning of the Cambrian period ( $~ 550$ million years ago). Micropaleontologists began to find evidence for Precambrian life in the 1960s in the form of fossilized bacteria in cherts. Presently, the oldest commonly agreed upon fossil microorganisms (it cannot be ascertained whether these organisms were archaebacteria, bacteria, or perhaps members of another no-longer-existent line of organism) are dated back to approximately 3.45 billion years ago (Schopf 1993). There is evidence in some of the oldest known rock 
strata for isotopically light carbon, possibly formed via biological activity, as far back as 3.85 billion years ago (Mojzsis et al. 1996). This notion remains controversial, and there is evidence that nonbiological processes could also produce this signal (Brasier et al. 2002).

Rocks returned from the moon suggest that there was a "late heavy bombardment period" in which there was an anomalously high flux of large meteors hitting the Earth 3.9 billion years ago (Abramov and Mojzsis 2009), which could have been planet-sterilizing. Thus, using the most conservative evidence for life on Earth and the most generous evidence for liquid water, there is about a one-giga year period of time for life to originate. Using the most controversial evidence for biologically fixed carbon and accepting the late heavy bombardment period as having been planet-sterilizing, there is a mere 50 million years available for the origin of life. Unfortunately, we cannot presently say whether the origin of life requires a week, a month, or a year, much less 50 million or a billion years, highlighting our ignorance of some of the key step in this process (Lazcano and Miller 1994).

\section{Top-Down and Bottom-Up Approaches}

Prebiotic chemistry attempts to not only produce organic compounds which could have been used to assemble the first living organisms, but also to explain the self-assembly of the first living organisms. For many researchers, the goal of prebiotic chemistry is the synthesis of a simple living system with some of the common attributes of modern cells, i.e., a lipid membrane, RNA and/or DNA, and small protein-like peptides. For the $\sim 60$ years since Miller's pioneering experiment, the synthesis of the components of modern cells has been the somewhat less ambitious goal. While the list of compounds which can be synthesized in the lab is impressive, not all modern cell constituents have been proven to be synthesizable under plausible prebiotic conditions, nor have all of them been found in meteorites. One possible explanation for this discrepancy is that some modern components are products of evolved biochemistry and were not added to the biochemical inventory until well after organisms had developed a considerable degree of complexity (Cleaves 2010).

We do not know which compounds were required for the origin of life. Prebiotic chemists tend to focus on compounds which are present in modern biochemistry, ignoring the large fraction of compounds found in meteorites or produced in simulations that are not found in biology. A recent study of the Murchison CC using sophisticated analytical instruments revealed the presence of many as around 14 million distinct low molecular weight organic compounds (Schmitt-Kopplin et al. 2010). This can be contrasted with the approximately 1,500 common metabolites found in contemporary cells (Morowitz 1979) and the some
600 small molecules positively identified in the Murchison meteorite to date (Table 2).

Our ignorance regarding the nature of the compounds required for the origin of life, though, does not stop us from attempting to understand how organic compounds form in prebiotic environments.

\section{Prebiotic Syntheses of Biochemicals}

\section{Amino Acids}

A variety of prebiotic processes can form amino acids, for example, Miller-Urey-type electric discharge experiments (Miller 1953) and reactions of HCN in water (Ferris et al. 1974), among others, and amino acids are found in a variety of CCs (Martins et al. 2007). One of the likely principal mechanisms of formation of amino acids in these samples is the Strecker synthesis (Fig. 4a), named for Adolf Strecker, a nineteenth-century chemist who was the first to artificially synthesize an amino acid in the laboratory. Evidence for this mechanism in the Miller-Urey (MU) experiment comes from measurements of the concentrations of $\mathrm{HCN}$, aldehydes, and ketones in the water flask produced during the course of the reaction (Fig. 4B), which are derived from the $\mathrm{CH}_{4}, \mathrm{NH}_{3}$, and $\mathrm{H}_{2}$ originally introduced into the apparatus. This suggests that amino acids are not formed directly in the electric discharge but are the result of synthesis involving aqueous-phase reactions (Miller 1955).

Both amino and hydroxy acids can be synthesized at high dilutions of $\mathrm{HCN}$ and aldehydes in a simulated primitive ocean (Miller 1957). Reaction rates depend on temperature, $\mathrm{pH}$, and $\mathrm{HCN}, \mathrm{NH}_{3}$, and aldehyde concentrations but are rapid on geologic time scales. The half-lives for the hydrolysis of the amino- and hydroxy-nitrile intermediates (the rate-limiting steps in these reactions) are less than 1,000 years at zero degrees Celsius (Miller 1998). Corroborating this notion of rapid synthesis, the amino acids found in the Murchison meteorite were apparently formed in less than $10^{5}$ years (Peltzer et al. 1984).

The Strecker amino acid synthesis requires the presence of $\mathrm{NH}_{3}$. As mentioned above, gaseous $\mathrm{NH}_{3}$ is rapidly decomposed by ultraviolet light, and during Archean times, the absence of a significant ozone layer would have limited $\mathrm{NH}_{3}$ 's atmospheric concentration. However, $\mathrm{NH}_{3}$ is extremely water soluble (depending on $\mathrm{pH}$ ) and similar in size to $\mathrm{K}^{+}$; thus, it easily enters exchange sites on clays. Thus, a considerable amount of $\mathrm{NH}_{3}$ may have been dissolved or adsorbed on submerged mineral surfaces.

Spark discharge experiments using $\mathrm{CH}_{4}, \mathrm{CO}$, or $\mathrm{CO}_{2}$ as a carbon source with various amounts of $\mathrm{H}_{2}$ show that methane is the best source of amino acids, but $\mathrm{CO}$ and $\mathrm{CO}_{2}$ are almost as good if a high $\mathrm{H}_{2} / \mathrm{C}$ ratio is used. Without added $\mathrm{H}_{2}$, amino acid yields are quite low, especially when $\mathrm{CO}_{2}$ is the sole carbon source (Stribling and Miller 1987). Recent 

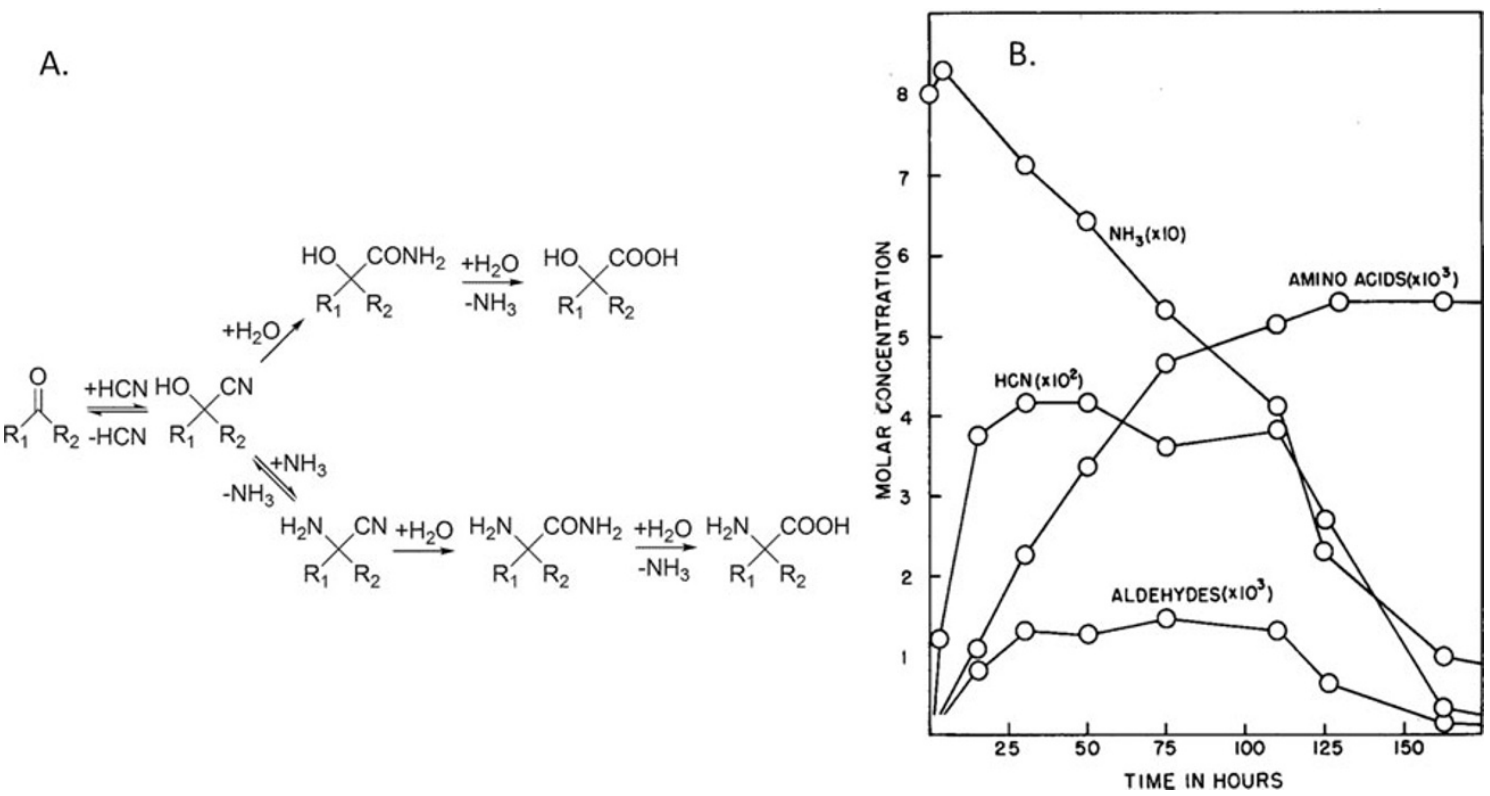

Fig. 4 Evidence for the Strecker amino acid synthesis and in the Miller-Urey experiment. a The cyanohydrin (top) and Strecker (bottom) mechanisms for the formation of hydroxy and amino acids from ammonia

results, however, suggest that amino acid yields from neutral atmospheres may be higher than previously thought. Buffering reaction $\mathrm{pH}$ near neutral (as dissolution of gaseous $\mathrm{CO}_{2}$ tends to lower the $\mathrm{pH}$ ) and adding oxidation inhibitors (which may counteract the oxidative effects of $\mathrm{NO}_{x}$ species generated in the reaction) increased the amino acid yields from $\mathrm{CO}_{2} / \mathrm{N}_{2} / \mathrm{H}_{2} \mathrm{O}$ electric discharge reactions several fold (Cleaves et al. 2008).

\section{Lipids and Membrane-Forming Compounds}

All modern life is cellular. Eukaryotic and bacterial cell membranes are composed of largely straight-chain fatty acid acyl glycerols while those of the archaea are composed of isoprenoid glycerol ethers (Ourisson and Nakatani 1994) (Fig. 5a, b). Either type could logically have been the primordial lipid component of cells, given uncertainties in rooting the tree of life. Long-chain fatty acids and their derivatives spontaneously form vesicles and micelles under appropriate conditions, and these can transiently trap various organic species and maintain proton gradients (Deamer et al. 2002).

Most prebiotic simulations don't generate large amounts of fatty acids (Allen and Ponnamperuma 1967), with the exception of some hydrothermal vent simulations, which may use concentrations of reactants which are unreasonably high for these environments (McCollom et al. 1999). Heating glycerol with fatty acids and urea produces acylglycerols (Hargreaves et al. 1977). A prebiotic synthesis of long-chain isoprenoids lipids has been suggested based on the Prins reaction of formaldehyde with isobutene (Ourisson and
$\left(\mathrm{NH}_{3}\right)$, hydrogen cyanide, and aldehydes or ketones. b Variations in the concentrations of ammonia, aldehydes, and hydrogen cyanide over the course of a Miller-Urey experiment. Fig. 4b reproduced from Miller (1957)

Nakatani 1994); thus, there are plausible prebiotic routes to these types of compounds.

The Murchison CC contains small amounts of straightchain fatty acids, though some of these may be contamination (Yuen and Kvenvolden 1973). Amphiphilic components have been observed in the Murchison meteorite and in various laboratory simulations of prebiotic chemistry (Dworkin et al. 2001) (Fig. 5c), though the composition of these remains undetermined.

Nucleic Acids

Modern organisms store their genetic information in DNA and transcribe it into RNA. The difference between these molecules is the use of deoxyribose and thymine in DNA
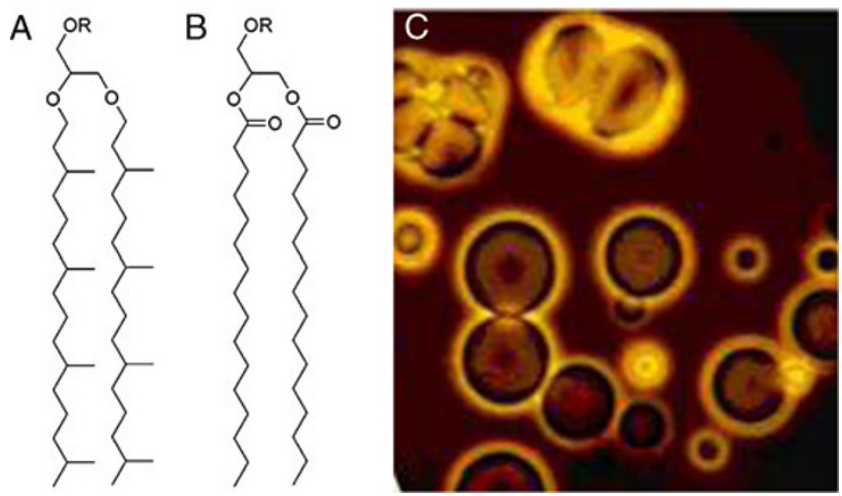

Fig. 5 Ether (a) and ester (b) lipids of biological membranes ( $\mathrm{R}$ can be various small molecule constituents including phosphate). $\mathbf{c}$ Micrograph of cell-like boundary structures formed spontaneously from organic extracts of the Murchison meteorite. Fig. 5c image courtesy of NASA 
and ribose and uracil in RNA. Although some now doubt that RNA itself is prebiotic, numerous laboratory experiments show the ease of formation of purines, pyrimidines, and sugars, albeit in low yield.

Purines

The first evidence that purines could be synthesized abiotically was provided in 1961 when Oró reported the formation of adenine (formally a pentamer of $\mathrm{HCN}, \mathrm{C}_{5} \mathrm{H}_{5} \mathrm{~N}_{5}$ ) from concentrated solutions of $\mathrm{NH}_{4} \mathrm{CN}$ refluxed for a few days. Adenine was produced up to $0.5 \%$ yield along with 4 -aminoimidazole- 5 carboxamide (AICA) and an intractable polymer (Oró and Kimball 1961). It is surprising that a synthesis requiring at least five steps should produce such high yields of adenine. The initial step is the dimerization of HCN followed by further reaction to give $\mathrm{HCN}$ trimer and $\mathrm{HCN}$ tetramer, diaminomaleonitrile (DAMN) (Fig. 6).

Ferris and Orgel (1966) demonstrated that a photochemical rearrangement of DAMN proceeds in high yield in sunlight to give amino imidazole carbonitrile (AICN) (Fig. 6). Other purines, including guanine, can be produced by variations of this synthesis from AICN and its amide (AICA) and other small molecules generated from HCN (Sanchez et al. 1967, 1968) (Fig. 6). These mechanisms are likely an oversimplification. In dilute solution, adenine synthesis may also involve the formation and rearrangement of precursors such as 2- and 8-cyano adenine (Voet and Schwartz 1983).<smiles>N#CC(N)C#N</smiles>

HCN Dimer

Aminomalononitrile (HCN Trimer)
Diaminomaleonitrile (DAMN)<smiles>N#CC(N)=C(N)C#N</smiles>

DAMN<smiles>N#CC(N)=C(N)C#N</smiles>

Diaminofumaronitrile<smiles>N#Cc1nc[nH]c1N</smiles>

Aminoimidazole

Carbonitrile

(AICN)

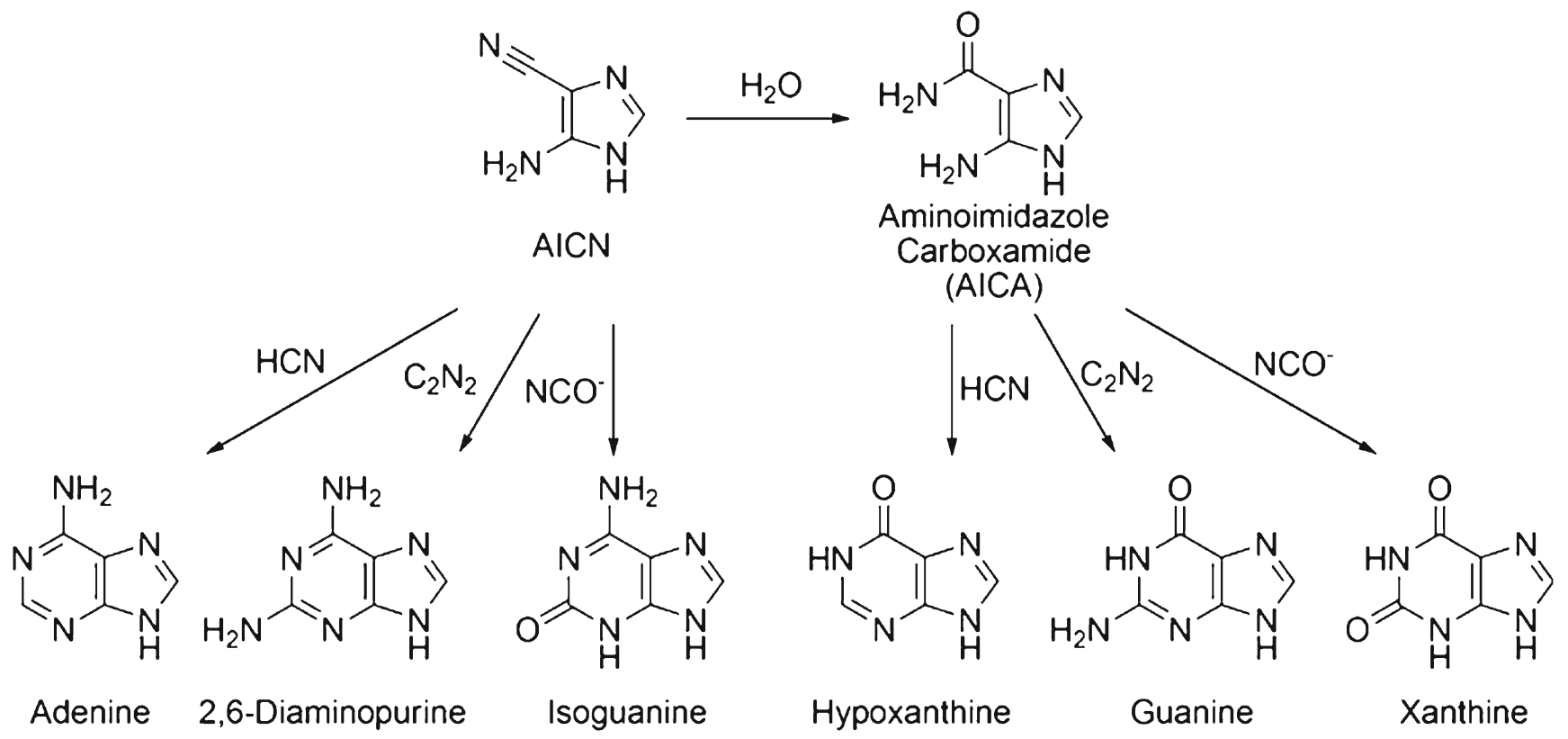

Fig. 6 Proposed mechanisms for formation of DAMN, AICN from DAMN, and purines from the reaction of AICN with small molecules produced in $\mathrm{HCN}$ oligomerization and MU-type experiments 
The steady-state concentration of $\mathrm{HCN}$ in primitive terrestrial waters would have depended on the $\mathrm{pH}$ and temperature of the oceans and the input rate of HCN from atmospheric synthesis. Assuming favorable $\mathrm{HCN}$ production rates, steady-state concentrations of $\mathrm{HCN}$ of $2 \times 10^{-6}$ molar at $\mathrm{pH}$ eight and zero degree Celsius in the primitive oceans have been estimated (Miyakawa et al. 2002b). At 100 degrees Celsius and $\mathrm{pH}$ eight, this was estimated at $7 \times$ $10^{-13}$ molar. Oligomerization and hydrolysis compete at approximately $10^{-2}$ molar concentrations of $\mathrm{HCN}$ at $\mathrm{pH}$ nine (Sanchez et al. 1966a, b), although it has been shown that adenine is still produced from solutions as dilute as $10^{-3}$ molar (Miyakawa et al. 2002a, b). If the concentration of $\mathrm{HCN}$ were as low as estimated, it is possible that DAMN formation may have only occurred on the primitive Earth in eutectic solutions of $\mathrm{HCN}-\mathrm{H}_{2} \mathrm{O}$, which would require that some regions of the Earth were frozen. High yields of DAMN are obtained by cooling dilute $\mathrm{HCN}$ solutions to negative ten to -30 degrees Celsius for a few months (Sanchez et al. 1966a, b). Production of adenine by HCN polymerization is accelerated by the presence of $\mathrm{HCHO}$ and other aldehydes, which could have also been available in the prebiotic environment (Schwartz and Goverde 1982).

The polymerization of concentrated $\mathrm{NH}_{4} \mathrm{CN}$ solutions also produces guanine between -80 and -20 degrees Celsius (Levy et al. 1999). Adenine, guanine, and amino acids have also been detected in dilute solutions of $\mathrm{NH}_{4} \mathrm{CN}$ kept frozen for 25 years at -20 and -78 degrees Celsius, as well as in the aqueous products of MU experiments frozen for five years at -20 degrees Celsius (Levy et al. 2000).

In addition to producing the biological purines, $\mathrm{HCN}$ oligomerization also produces nonbiological purines such as 2,6-diamino- and dioxopurines and the parent compound purine. This same suite of purines has been identified in CCs (Callahan et al. 2011), making a compelling case that similar mechanisms are responsible for their syntheses in CCs.

Formamide $\left(\mathrm{HCONH}_{2}\right)$, the hydrolysis product of $\mathrm{HCN}$, has also been shown to produce purines, albeit under more extreme conditions (Bredereck et al. 1961; Saladino et al. 2007).

\section{Pyrimidines}

The first "prebiotic" synthesis of pyrimidines investigated was that of uracil (U) from malic acid and urea (Fox and Harada 1961). The prebiotic synthesis of cytosine (C) from cyanoacetylene $(\mathrm{HCCCN})$ and cyanate $\left(\mathrm{NCO}^{-}\right)$ was later described (Sanchez et al. 1966a, b; Ferris et al. 1968) (Fig. 7). HCCCN is produced by the action of spark discharges on $\mathrm{CH}_{4} / \mathrm{N}_{2}$ mixtures, and $\mathrm{NCO}^{-}$is produced from cyanogen or the decomposition of urea.
The high concentrations of $\mathrm{NCO}^{-}$required for this reaction may be unrealistic, as it rapidly hydrolyzes to $\mathrm{CO}_{2}$ and $\mathrm{NH}_{3}$. Urea is more stable, depending on the concentrations of $\mathrm{NCO}^{-}$and $\mathrm{NH}_{3}$. It was later found that the reaction of dilute cyanoacetaldehyde (CAA) (produced from the hydrolysis of $\mathrm{HCCCN}$ ) with urea concentrated by evaporation in laboratory simulations of drying beaches gives large $(>50 \%)$ yields of $\mathrm{C}$ (Robertson 1995) (Fig. 7). Evaporating CAA with guanidine produces 2, 4-diaminopyrimidine in high yield (Robertson et al. 1996), which hydrolyses to $U$ and C, providing a mechanism for the accumulation of pyrimidines in the prebiotic environment. A eutectic reaction producing the biological pyrimidines has also been demonstrated (Cleaves et al. 2006). U (albeit in low yields) and its biosynthetic precursor orotic acid were also identified in the hydrolysis products of HCN polymer (Ferris et al. 1978; Voet and Schwartz 1982), and U has been identified in CCs (Stoks and Schwartz 1979).

The reaction of $U$ with formaldehyde and formate gives thymine (T) in good yield (Choughuley et al. 1977). T is also synthesized from the UV-catalyzed dehydrogenation of dihydrothymine, produced from the reaction of $\beta$-aminoisobutryic acid with urea (Schwartz and Chittenden 1977).

\section{Sugars}

Many biological sugars have the empirical formula $\left(\mathrm{CH}_{2} \mathrm{O}\right)_{n}$, a point underscored by Butlerov's 1861 discovery of the formose reaction, which showed that a diverse assortment of sugars can be formed by the reaction of $\mathrm{HCHO}$ under basic conditions (Butlerow 1861). The Butlerov synthesis is complex and incompletely understood. It depends on the presence of catalysts, with $\mathrm{Ca}(\mathrm{OH})_{2}$ or $\mathrm{CaCO}_{3}$ being the most completely investigated. In the absence of base catalysts, little or no sugar is obtained. Clays such as kaolin catalyze the formation of sugars, including ribose, in small yields from dilute (0.01 molar) HCHO solutions (Gabel and Ponnamperuma 1967; Reid and Orgel 1967; Schwartz and Degraaf 1993).

The Butlerov synthesis is autocatalytic and proceeds through glycoaldehyde, glyceraldehyde, and dihydroxyacetone. The reaction is also catalyzed by glycolaldehyde, acetaldehyde, and various other organic catalysts (Matsumoto et al. 1984).

The reaction may proceed as shown in Fig. 8. The reaction tends to stop when the formaldehyde has been consumed and ends with the production of $\mathrm{C} 4-\mathrm{C} 7$ sugars that can form cyclic acetals and ketals.

The reaction produces all of the epimers and isomers of the small $\mathrm{C} 2-\mathrm{C} 6$ sugars, some of the $\mathrm{C} 7$ ones, and various dendroaldoses and dendroketoses, as well as polyols such as 
Fig. 7 Possible mechanisms for the prebiotic synthesis of pyrimidines from the reaction of $\mathrm{HCCCN}$ or CAA with urea concentrated in drying lagoon models

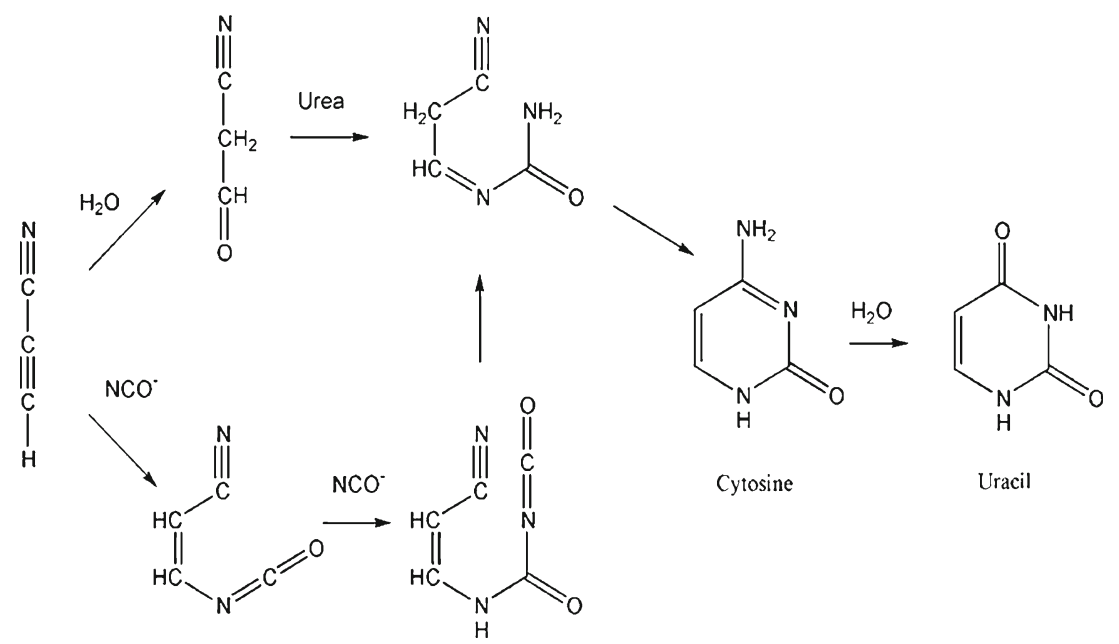

glycerol and pentaerythritol, and is generally not particularly selective, although methods of overcoming this have been investigated. Of special interest is the observation that borate can skew the product mixture in favor of certain sugars, including ribose (Prieur 2001; Ricardo et al. 2004). Inclusion of acetaldehyde in the reaction produces deoxyribose (Oró 1965).

Problems with the formose reaction as a source of sugars on the primitive Earth have been noted. One is the complexity of the product mixture. More than 40 different sugars were identified in one reaction mixture (Decker et al. 1982). Another problem is that the conditions of synthesis are also conducive to the degradation of sugars (Reid and Orgel 1967). Sugars undergo various reactions on short geological time scales that are seemingly prohibitive to their accumulation in the environment. At $\mathrm{pH}$ seven, the half-life for ribose decomposition is 73 minutes at 100 degrees Celsius and 44 years at zero degree Celsius (Larralde et al. 1995). Most other sugars are similarly labile.

Additionally, when aqueous solutions of $\mathrm{HCN}$ and $\mathrm{HCHO}$ are mixed, the major product is glycolonitrile (Schlesinger and Miller 1973), which could preclude the formation of sugars and purines in the same location (Arrhenius et al. 1994). Nevertheless, both sugar derivatives and nucleic acid bases

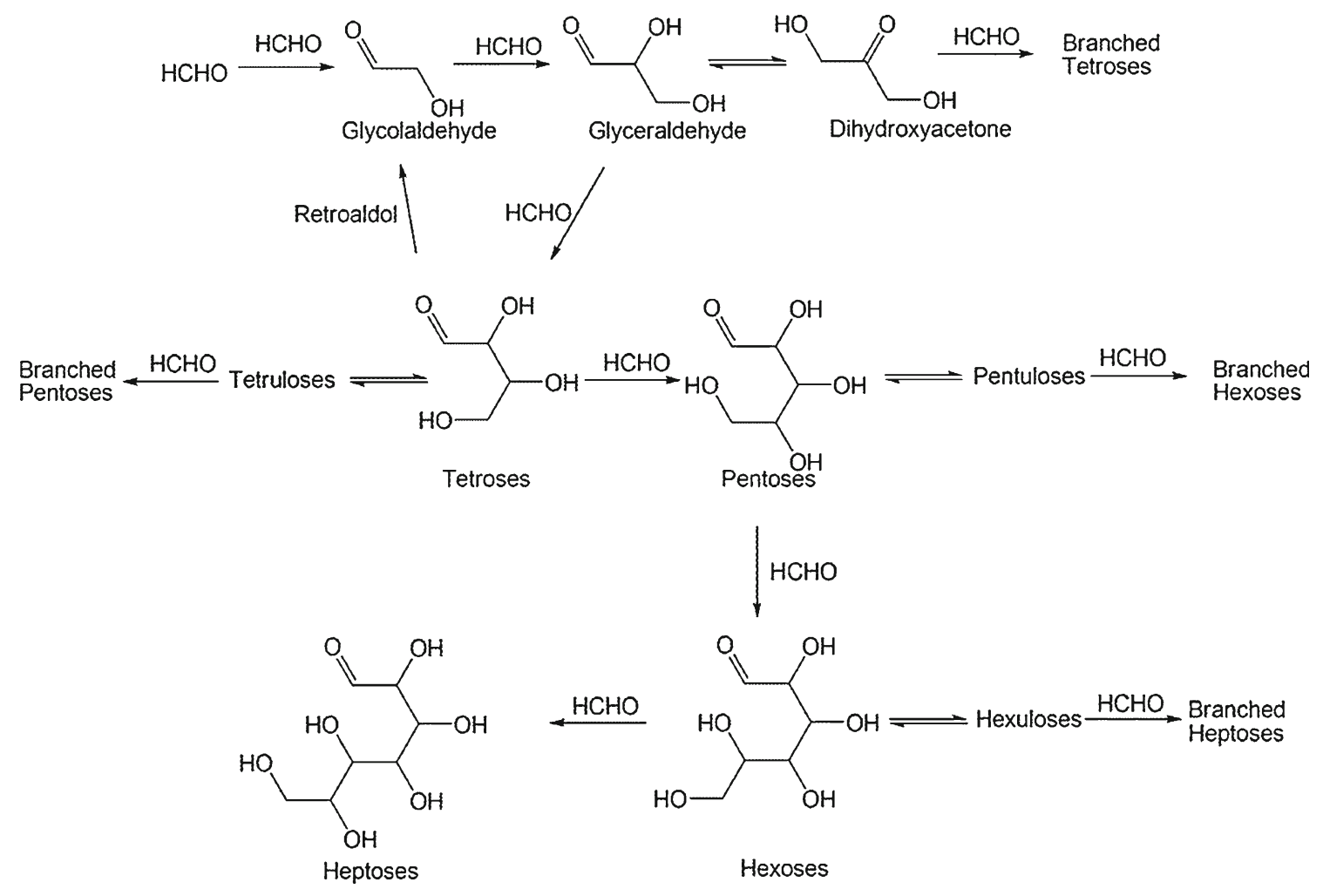

Fig. 8 A simplified scheme of the formose reaction 
have been found in the Murchison meteorite (Cooper et al. 2001; Callahan et al. 2011), and it seems likely that the chemistry which produced the compounds found in Murchison meteorite was from aqueous reactions of simple species such as HCN and HCHO. This suggests that the synthesis of sugars, amino acids, and purines from $\mathrm{HCHO}$ and $\mathrm{HCN}$ may take place under certain conditions.

\section{Nucleosides, Nucleotides}

The earliest attempts to produce nucleosides prebiotically involved simply heating purines or pyrimidines in the dry state with ribose (Fuller et al. 1972). Using hypoxanthine and a mixture of salts reminiscent of those found in seawater, up to eight $\%$ of $\beta$-D-inosine was formed, along with the $\alpha$-isomer. Adenine and guanine gave lower yields, and in both cases, a mixture of $\alpha$ - and $\beta$-isomers was obtained (Fuller et al. 1972). Direct heating of ribose and U or C has thus far failed to produce uridine or cytidine. Pyrimidine nucleoside syntheses have been demonstrated which start from ribose, cyanamide, and cyanoacetylene; however, $\alpha$-Dcytidine is the major product (Sanchez and Orgel 1970). This can be photo-anomerized to $\beta$-D-cytidine in low yield. Sutherland and coworkers (Ingar et al. 2003) demonstrated that cytidine-3'-phosphate can be prepared from arabinose3-phosphate, cyanamide, and HCCCN in a one-pot reaction. The prebiotic source of arabinose-3-phosphate is unclear; nevertheless, it remains possible that more creative methods of prebiotic pyrimidine nucleoside synthesis can be found.

More recently, reactions using more complex reagents added in precise orders, with the products isolated and carried through to the next step, have been shown to produce significant yields of ribotides (Powner et al. 2007). These reactions give good yields of the pyrimidine ribotides (Powner and Sutherland 2008), and a related series of reactions could produce the purine ribotides (Powner et al. 2010). It is not clear that these syntheses solve previously raised objections to the plausibility of prebiotic nucleoside and nucleotide synthesis (Shapiro 1984).

Prebiotic phosphorylation of nucleosides has also been demonstrated, but again with caveats. Small amounts of condensed phosphates are emitted in volcanic fumaroles (Yamagata et al. 1991), and heating orthophosphate at relatively low temperatures in the presence of ammonia results in a high yield of condensed phosphates (Osterberg and Orgel 1972). Trimetaphosphate (TMP) has been shown to be an active phosphorylating agent for various molecules including amino acids and nucleosides (Schwartz 1969; Rabinowitz and Hampai 1978; Yamagata et al. 1991). However, it has also been suggested that condensed phosphates are not likely to be prebiotically abundant materials (Keefe and Miller 1995).

Early attempts to produce nucleotides using organic condensing reagents such as $\mathrm{H}_{2} \mathrm{CN}, \mathrm{NCO}^{-}$, or dicyanamide
(Lohrmann and Orgel 1968) were generally inefficient due to the competition of the alcohol groups of the nucleosides with water in an aqueous environment. Nucleosides can be phosphorylated with acidic phosphates such as $\mathrm{NaH}_{2} \mathrm{PO}_{4}$ when dry heated (Beck et al. 1967). These reactions are catalyzed by urea and other amides, particularly if $\mathrm{NH}_{3}$ is included in the reaction. Nucleosides can also be phosphorylated in high yield by heating ammonium phosphate with urea at moderate temperatures, as might occur in a drying lagoon (Lohrmann and Orgel 1971). Heating uridine with urea and ammonium phosphate gave yields of nucleotides as high as $70 \%$. In the case of purine nucleotides, however, there is also considerable glycosidic cleavage due to the acidic microenvironment created. Thus, another problem with the "prebiotic" RNA world is that the synthesis of purine nucleosides is somewhat robust, but nucleotide formation may be difficult, while nucleotide formation from pyrimidine nucleosides is robust, but nucleoside formation may be difficult.

Common calcium phosphate minerals such as apatite are themselves reasonable phosphorylating reagents. Yields as high as $20 \%$ of nucleotides were achieved by heating nucleosides with apatite, urea, and ammonium phosphate (Lohrmann and Orgel 1971). Heating ammonium phosphates with urea leads to a mixture of high molecular weight polyphosphates (Osterberg and Orgel 1972). Although these are not especially good phosphorylating reagents under prebiotic conditions, they may degrade, especially in the presence of divalent cations at high temperatures, to cyclic phosphates such as TMP.

The difficulties with prebiotic ribose synthesis and nucleoside formation have led some to speculate that perhaps a simpler genetic molecule with a more robust prebiotic synthesis preceded RNA (Joyce et al. 1987). Substituting sugars besides ribose has been proposed (Eschenmoser 2004). Oligomers of some of these also form stable base-paired structures with both RNA/DNA and themselves, opening the possibility of genetic takeover from a precursor polymer to RNA/DNA. Such molecules may suffer from the same drawbacks as RNA with respect to prebiotic chemistry, such as the difficulty of selective sugar synthesis, sugar instability, and the difficulty of nucleoside formation. It has been demonstrated based on the suggestion of Joyce et al. (1987) and proposed chemistry (Nelsestuen 1980; Tohidi and Orgel 1989) that backbones based on acyclic nucleoside analogs may be more easily obtained under reasonable prebiotic conditions, for example by the reaction of nucleobases with acrolein obtained from mixed formose reactions (Cleaves 2002).

More exotic alternatives to nucleosides have been proposed, for example peptide nucleic acid (PNA) analogs (Nielsen et al. 1994). Miller and coworkers were able to demonstrate the prebiotic synthesis of the components of PNA under the same chemical conditions required for the synthesis of the purines or pyrimidines (Nelson et al. 2000). 
The vast majority of possible alternative structures have not been investigated with respect to prebiotic plausibility.

\section{Environmental Considerations}

Whether in meteorites or on Earth, prebiotic chemistry may have occurred largely in an aqueous environment, as water is a ubiquitous component of the solar system and the Earth's surface. Among the variables of the local environment which could affect the way this chemistry occurs are $\mathrm{pH}$, temperature, inorganic compounds such as metals, mineral surfaces, the impact of sunlight, etc. The potential role of mineral surfaces on prebiotic chemistry is an especially complex and under-explored aspect of this chemistry. Although we do not presently know which compounds were essential for the origin of life, it seems possible to preclude certain environments if even fairly simple organic compounds were involved (Cleaves and Chalmers 2004).

\section{Stability of Biomolecules at High Temperatures}

High temperatures cause reactions to occur more quickly, they are also destructive to most bioorganic compounds. Although some progress has been made in synthesizing small molecules under conditions simulating hydrothermal vents, most biological molecules have hydrolytic half-lives on the order of minutes to seconds at the temperatures associated with on-axis hydrothermal vents and are still rather unstable at the lower temperatures of off-axis vent environments. Ribose and other sugars are extremely thermolabile (Larralde et al. 1995), but pyrimidines and purines, and many amino acids, are nearly as labile. At 100 degrees Celsius, the half-life $\left(t_{1 / 2}\right)$ for deamination of cytosine is 21 days, and 204 days for adenine (Levy and Miller 1998). Some amino acids are more stable: alanine has a $t_{1 /}$ 2 for decarboxylation of $\sim 1.9 \times 10^{4}$ years at 100 degrees Celsius, but serine decarboxylates to ethanolamine with a $t_{1 /}$ ${ }_{2}$ of 320 days (Vallentyne 1964). White (1984) measured the decomposition of various compounds at 250 degrees Celsius and $\mathrm{pH}$ seven and found $t_{1 / 2}$ values for amino acids from 7.5 seconds to 278 minutes, peptide bonds from less than one minute to 11.8 minutes, glycoside cleavage in nucleosides from less than one second to 1.3 minutes, decomposition of nucleobases from 15 to 57 minutes, and phosphate esters from 2.3 to 420 minutes. The half-lives for polymers would be even shorter as there are so many more potential breakage points.

\section{Minerals}

There are approximately 4,400 known naturally occurring minerals on Earth today (Hazen et al. 2008). This number was likely smaller on the early Earth, as many minerals are produced by oxidation with environmental $\mathrm{O}_{2}$, biological deposition, or the vast amounts of time which have passed since the Earth formed.

Minerals may have complex effects on prebiotic organic synthesis (Lahav and Chang 1976) by concentrating reactants and by lowering activation barriers to bring compounds into more rapid equilibrium (Marshall-Bowman et al. 2010).

\section{Shallow Pools}

Since Darwin's time, it has been supposed that life may have originated in shallow tidal pools. Possible advantages of such environments include evaporative concentration, constrained diffusion mineral catalysis, and the penetration of sunlight into such pools. Additionally, if the Earth's surface was colder at this time, or at least as clement as at present, then it is possible that periodic freezing events could have significantly concentrated compounds.

\section{Hydrothermal Vents}

The discovery of hydrothermal vents at mid-ocean ridges and the appreciation of their significance in the element balance of the hydrosphere were a major discovery in oceanography (Corliss et al. 1979). Since the process of hydrothermal circulation probably began early in Earth's history, it is likely that vents were also present. Large amounts of ocean water now pass through the vents, with the whole ocean going through them approximately every ten million years (Edmond et al. 1982). This flow was probably greater during the early history of the Earth, since the heat flow from the planet's interior was greater. The topic has received a great deal of attention, partly because of uncertainty regarding the oxidation state of the early atmosphere.

There are various types of hydrothermal environments on the modern Earth, including subaerial hot springs and submarine hydrothermal vents. In the latter, temperatures range from $\sim$ four to 350 degrees Celsius, with $\mathrm{pH}$ ranging from zero to 11 (Martin et al. 2008). Various minerals precipitate as the heated vent water enters the surrounding ocean water, leading to the formation of baroque rock formations. It has been speculated that the pores in such minerals may have served to concentrate organic species via thermophoresis (Baaske et al. 2007).

Following the vents' discovery, a hypothesis suggesting a hydrothermal emergence of life was published (Corliss et al. 1981), which suggested that amino acids and other organic compounds could be produced during passage of the effluent through the temperature gradient from $~ 350$ degrees Celsius to $\sim$ zero degree Celsius, roughly the temperature of modern ambient ocean waters. 
Polymerization of the organic compounds thus formed, followed by their self-organization, was also proposed in this environment.

At first glance, submarine hydrothermal springs appear to be ideally suited for organic synthesis, given the geological plausibility of a hot early Earth. Vents exist along the active tectonic areas of the Earth, and in at least some of them, potentially catalytic minerals interact with an aqueous reducing environment rich in $\mathrm{H}_{2}, \mathrm{H}_{2} \mathrm{~S}, \mathrm{CO}, \mathrm{CO}_{2}, \mathrm{CH}_{4}$, and $\mathrm{NH}_{3}$. Unfortunately, it is difficult to corroborate these speculations with the composition of the effluents of modern vents, as much of the organic material released from modern sources is simply environmentally processed biological material.

Modern hydrothermal vent fluids do contain some organic compounds, though it remains unclear what percentage are derived from organisms living in the vents or biologically derived matter entrained into the vent fluids and reworked, and what percentage is derived from truly abiotic processes. For example, for amino acids, the bulk of the evidence available supports a biological origin (Bassez et al. 2009). Presently, the amount and type of organic matter found in hydrothermal vent environments unequivocally thought to be of abiotic origin are limited to a few parts per million of small hydrocarbons such as $\mathrm{CH}_{4}$ and ethane (McCollom et al. 2010).

One of the most articulate autotrophic vent origin-of-life hypotheses stems from the work of Wächtershäuser (1988, 1992), who argued that life began with the appearance of an autocatalytic, two-dimensional chemolithotrophic metabolic system based on the formation of the insoluble mineral pyrite $\left(\mathrm{FeS}_{2}\right)$. The $\mathrm{FeS} / \mathrm{H}_{2} \mathrm{~S}$ combination is a strong reducing agent and has been shown to reduce some organic compounds under mild conditions. Wächtershäuser's scenario fits well with the environmental conditions found at deep-sea hydrothermal vents, where $\mathrm{H}_{2} \mathrm{~S}, \mathrm{CO}_{2}$, and $\mathrm{CO}$ are abundant; however, the $\mathrm{FeS} / \mathrm{H}_{2} \mathrm{~S}$ system does not reduce $\mathrm{CO}_{2}$ to amino acids, purines, or pyrimidines, although there is more than enough free energy to do so (Keefe et al. 1995). Pyrite formation can produce molecular hydrogen and reduce nitrate to $\mathrm{NH}_{3}$, and $\mathrm{HCCH}$ to $\mathrm{H}_{2} \mathrm{CCH}_{2}$ (Maden 1995). More recent experiments have shown that the activation of amino acids with carbon monoxide and $(\mathrm{Ni}, \mathrm{Fe}) \mathrm{S}$ can lead to peptide bond formation (Huber and Wachtershauser 1998), though the degree to which these experiments mimic geochemical environments is a subject of debate.

In general, organic compounds are decomposed rather than created at hydrothermal vent temperatures, although temperature gradients exist. Sowerby and coworkers have shown (Sowerby et al. 2001) that concentration on mineral surfaces would tend to concentrate organics created at hydrothermal vents in cooler zones. The presence of reduced metals at high temperatures could facilitate Fischer-Trospch-type (FTT) syntheses. FTT catalysts are poisoned by water and sulfide, though some of the likely catalysts such as magnetite may be immune to such poisoning (Holm and Andersson 1998).

Submarine hydrothermal vents do not seem to presently synthesize organic compounds more complex than simple hydrocarbons such as $\mathrm{CH}_{4}$ and ethane (McCollom et al. 2010). More likely, they decompose them over short time spans ranging from seconds to a few hours. The origin of life in hydrothermal vents thus may be problematic.

This does not imply that hydrothermal vents were a negligible factor on the primitive Earth. If mineral assemblages were sufficiently reducing, vents may have been a source of atmospheric $\mathrm{NH}_{3}, \mathrm{CO}, \mathrm{CH}_{4}$, and $\mathrm{H}_{2}$. The concentrations of biomolecules in primitive Earth environments would have been governed by the rates of production and the rates of destruction. Submarine hydrothermal vents would have likely been more important for the destruction of organic compounds, fixing the upper limit for their concentrations in the primitive oceans.

\section{Prebiotic Chemistry Beyond Earth}

Of the eight accepted planets in our solar system and their moons, several appear compatible with the synthesis of organic compounds, and several are known to contain them. Fewer appear to be compatible with the existence of liquid water or the more complicated evolution of these compounds. For example, the extreme temperatures of Venus' or Mercury's sunlit side are likely too hostile for the synthesis of complex organics. The immediate sub-surface of Mars appears to harbor both liquid and solid water (Rennó et al. 2009), and it is widely believed that liquid water once flowed on Mars' surface. Meteorites likely impacted Mars' surface at this time, and it is reasonable to expect that some of these were CCs. The nature of Mars' early atmosphere remains unknown, but Mars and Earth may have been similar early in their history.

Proceeding outward from the Sun, complex organic chemistry likely occurs in the atmospheres of Saturn and Jupiter. The conditions on the solid surfaces of these planets are thought to be too hostile for more complex organic chemistry. Nevertheless, the presence of various organic species has been confirmed in their atmospheres (Lodders 2010).

\section{Outer-Planet Moons}

A number of outer-planet moons have intriguing environments which appear to foster prebiotic chemistry and could conceivably be capable of sustaining biology. For example, Saturn's moon Titan is now known to harbor a rich organic chemistry (Waite et al. 2007). Jupiter's moon Europa is covered with a thick ice layer which may harbor a watery 
ocean several kilometers thick (Manga and Wang 2007). If this ocean does exist, its organic content remains unknown.

\section{Extrasolar Planets}

For centuries, the existence of planets beyond our solar system has been the subject of intense philosophical and scientific speculation (Urey et al. 1963; Dick 1999). The first extrasolar planet was confirmed in 2003 (Hatzes et al. 2003). Recent astronomical observations have since yielded hundreds of planets orbiting other suns (http://www.exoplanet.eu/; http:// nsted.ipac.caltech.edu/). Methods to date have favored the detection of large planets with orbits very close to their parent suns, but soon, advances will allow detection of smaller planets with orbits compatible with the existence of liquid surface water. Our solar system contains three rocky Earth-like planets, two of which are almost in the habitable zone.

There is no solid reason to expect that our solar system is anomalous. Given the billions of Sun-like stars in any galaxy, there may be many rocky Earth-like planets in stellar habitable zones in the universe (Laughlin 2010), some of which may have undergone similar periods of evolution compatible with the origin and evolution of life. The detection of such planets and possible signatures of alien biochemistry may not be far off, assuming that the origin of life is facile. The detection of even one such planet would strongly reinforce the idea that it is.

\section{Unknowns and the Future}

A basic tenet of the heterotrophic theory of the origin of life is that the origin of the first living systems depended on environmentally supplied organic molecules. As summarized here, there has been no shortage of discussion as to how the formation of these molecules occurred. Organic compounds may have accumulated on the primitive Earth via numerous mechanisms including contributions from endogenous atmospheric synthesis, deep-sea hydrothermal vent synthesis, and exogenous delivery. Though this raises the issue of the relative significance of the various sources, it also recognizes the wide variety of potential sources of organic compounds.

Given adequate expertise and experimental conditions, it is possible to synthesize many organic molecules in the laboratory under simulated prebiotic conditions. The fact that a number of molecular components of contemporary cells can be formed in the laboratory does not necessarily mean that they were essential for the origin of life, or that they were likely prebiotically available. The Earths' primordial soup may have been a complex mixture, but it likely did not include all of the compounds found today in even the simplest cells.
There are many mechanisms by which biochemical monomers can be prebiotically synthesized. Not all prebiotic pathways are equally efficient, but the wide range of conditions under which organic compounds can be synthesized demonstrates that prebiotic syntheses of the building blocks of life are robust, i.e., they can occur in a wide variety of environmental settings. Although our ideas regarding the prebiotic synthesis of organic compounds are based largely on model experiments, the robustness of this type of chemistry is supported by the occurrence of many of these compounds in CCs. It is therefore plausible that a similar synthesis took place on the primitive Earth.

We do not yet have a coherent model for how life arose on Earth or how it might arise on other planets. We do, however, have evidence that many organic compounds, including many of those crucial to the functioning of modern organisms, are easily produced via prebiotic chemistry and are likely widespread throughout the universe. We also know that in some cases, some of these spontaneously selforganize.

It is impossible to predict how soon the problems prebiotic chemistry addresses will be solved. It seems likely that in the near future, chemists will assemble living organisms de novo. As of this writing, an entire synthetic genome was constructed (Gibson et al. 2008), a ribozyme capable of assembling $80 \%$ of its sequence was developed in the laboratory (Wochner et al. 2011), and a self-sustained and autocatalytic set of self-propagating RNA molecules had been culled from a laboratory experiment (Lincoln and Joyce 2009).

What remains more problematic is a comprehensive understanding of how such systems may have arisen from environmentally plausible reactions on the primitive Earth. Despite considerable progress, much work remains, and undoubtedly, many surprises are in store.

Acknowledgments The author would like to thank Professor Antonio Lazcano (UNAM) for inviting the contribution of this manuscript and the NASA and NSF-funded Center for Chemical Evolution for generous support during its preparation.

\section{References}

Abramov O, Mojzsis SJ. Microbial habitability of the Hadean Earth during the late heavy bombardment. Nature. 2009;459 (7245):419-22.

Alexander CMOD, Fogel M, et al. The origin and evolution of chondrites recorded in the elemental and isotopic compositions of their macromolecular organic matter. Geochim Cosmochim Acta. 2007;71(17):4380-403.

Allen WV, Ponnamperuma C. A possible prebiotic synthesis of monocarboxylic acids. Curr Mod Biol. 1967;1(1):24-8.

Anders E. Pre-biotic organic-matter from comets and asteroids. Nature. 1989;342(6247):255-7. 
Arrhenius T, Arrhenius G, et al. Archean geochemistry of formaldehyde and cyanide and the oligomerization of cyanohydrin. Orig Life Evol Biosph. 1994;24(1):1-17.

Arrhenius G, Bada JL, Joyce GF, Lazcano A, Miller S, Orgel LE. Origin and ancestor: separate environments. Science. 1999;283 (5403):792.

Baaske P, Weinert FM, et al. Extreme accumulation of nucleotides in simulated hydrothermal pore systems. Proc Natl Acad Sci. 2007;104(22):9346-51

Bada JL, Miller SL. Ammonium ion concentration in the primitive ocean. Science. 1968;159(813):423-5.

Bassez M-P, Takano Y, et al. Organic analysis of peridotite rocks from the Ashadze and Logatchev hydrothermal sites. Int J Mol Sci. 2009;10(7):2986-98.

Beck A, Lohrmann R, et al. Phosphorylation with inorganic phosphates at moderate temperatures. Science. 1967;157(3791):952.

Bockelée-Morvan D, Lis DC, Wink JE, Despois D, Crovisier J, Bachiller $\mathrm{R}$, et al. New molecules found in comet C/1995 O1 (Hale-Bopp). Investigating the link between cometary and interstellar material. Astron Astrophys. 2000;353:1101-14.

Brasier MD, Green OR, et al. Questioning the evidence for Earth's oldest fossils. Nature. 2002;416(6876):76-81.

Bredereck H, Effenberger F, et al. Eine neue einfache Purin-Synthese. Angew Chem. 1961;73(2):63

Butlerow A. Formation synthetique d'une substance sucree. C R Acad Sci. 1861;53:145-7.

Callahan MP, Smith KE, et al. Carbonaceous meteorites contain a wide range of extraterrestrial nucleobases. Proc Natl Acad Sci. 2011;108(34):13995-8.

Chameides WL, Walker JCG. Rates of fixation by lightning of carbon and nitrogen in possible primitive atmospheres. Orig Life Evol Biosph. 1981;11(4):291-302.

Choughuley AS, Subbaraman AS, et al. A possible prebiotic synthesis of thymine: uracil-formaldehyde-formic acid reaction. Biosystems. 1977;9(2-3):73-80.

Chyba CF. Impact delivery and erosion of planetary oceans in the early inner solar system. Nature. 1990;343(6254):129-33.

Chyba C, Sagan C. Endogenous production, exogenous delivery and impact-shock synthesis of organic molecules: an inventory for the origins of life. Nature. 1992;355:125-32.

Chyba C, Thomas $\mathrm{P}$, et al. Cometary delivery of organic molecules to the early Earth. Science. 1990;249(4967):366-73.

Cleaves 2nd HJ. The reactions of nitrogen heterocycles with acrolein: scope and prebiotic significance. Astrobiology. 2002;2(4):40315.

Cleaves HJ. Prebiotic chemistry, the primordial replicator, and modern protocells. In: Steen Rasmussen MAB, Chen L, Deamer D, Packard NH, Krakauer DC, Stadler PF, editors. Protocells. Bridging nonliving and living matter. Cambridge: The MIT Press; 2008. p. 583-614.

Cleaves 2nd HJ. The origin of the biologically coded amino acids. J Theor Biol. 2010;263(4):490-8.

Cleaves 2nd HJ, Chalmers JH. Extremophiles may be irrelevant to the origin of life. Astrobiology. 2004;4(1):1-9.

Cleaves HJ, Lazcano A. The origin of biomolecules. In: Zaikowski L, Friedrich JM, Seidel SR, editors. Chemical evolution II: from origins of life to modern society. New York: Oxford University Press; 2009. p. 17-43.

Cleaves HJ, Miller SL. Oceanic protection of prebiotic organic compounds from UV radiation. Proc Natl Acad Sci USA. 1998;95 (13):7260-3.

Cleaves 2nd HJ, Nelson KE, et al. The prebiotic synthesis of pyrimidines in frozen solution. Naturwissenschaften. 2006;93(5):228-31.

Cleaves HJ, Chalmers JH, et al. A reassessment of prebiotic organic synthesis in neutral planetary atmospheres. Orig Life Evol Biosph. 2008;38(2):105-15.
Clemett SJ, Maechling CR, et al. Identification of complex aromatic molecules in individual interplanetary dust particles. Science. 1993;262(5134):721-5.

Cooper G, Kimmich N, et al. Carbonaceous meteorites as a source of sugar-related organic compounds for the early Earth. Nature. 2001;414(6866):879-83.

Corliss JB, et al. Submarine thermal springs on the Galapagos Rift. Science. 1979;203:1073-83.

Corliss J, Baross J, et al. An hypothesis concerning the relationship between submarine hot springs and the origin of life on Earth. Oceanol Acta. 1981;4 Supplement:59-69.

Crick FHC. The origin of the genetic code. J Mol Biol. 1968;38 (3):367-79.

Dalrymple GB. The age of the Earth. Stanford: Stanford University Press; 1994.

Deamer D, Dworkin JP, et al. The first cell membranes. Astrobiology. 2002;2(4):371-81.

Decker P, Schweer H, et al. Bioids: X. Identification of formose sugars, presumable prebiotic metabolites, using capillary gas chromatography/gas chromatography - mas spectrometry of n-butoxime trifluoroacetates on OV-225. J Chromatogr A. 1982;244(2):281-91.

Dick SJ. The biological universe: the twentieth century extraterrestrial life debate and the limits of science. Cambridge University Press: Cambridge; 1999.

Dworkin JP, Deamer DW, et al. Self-assembling amphiphilic molecules: synthesis in simulated interstellar/precometary ices. Proc Natl Acad Sci USA. 2001;98(3):815-9.

Edmond JL, Von Damm KL, et al. Chemistry of hot springs on the East Pacific Rise and their effluent dispersal. Nature. 1982;297:187-91.

Ehrenfreund P, Charnley SB. Organic molecules in the interstellar medium, comets, and meteorites: a voyage from dark clouds to the early Earth. Annu Rev Astron Astrophys. 2000;38:427-83.

Elsila JE, Glavin DP, et al. Cometary glycine detected in samples returned by Stardust. Meteorit Planet Sci. 2009;44(9):1323-30.

Eschenmoser A. The TNA-family of nucleic acid systems: properties and prospects. Orig Life Evol Biosph. 2004;34(3):277-306.

Ferris JP, Nicodem DE. Ammonia photolysis and the role of ammonia in chemical revolution. Nature. 1972;238(5362):268-9.

Ferris JP, Orgel LE. Studies on prebiotic synthesis. I. Aminomalononitrile and 4-amino-5-cyanoimidazole. J Am Chem Soc. 1966;88 (16):3829-31.

Ferris JP, Sanchez RA, et al. Studies in prebiotic synthesis: III. Synthesis of pyrimidines from cyanoacetylene and cyanate. J Mol Biol. 1968;33(3):693-704.

Ferris JP, Wos JD, et al. Chemical evolution. XXI. The amino acids released on hydrolysis of HCN oligomers. J Mol Evol. 1974;3(3):225-31.

Ferris JP, Joshi PC, et al. HCN: a plausible source of purines, pyrimidines and amino acids on the primitive earth. J Mol Evol. 1978;11 (4):293-311.

Festou M, Keller HU, et al. Comets II. Tucson: University of Arizona Press; Lunar and Planetary Institute; 2004.

Fox SW, Harada K. Synthesis of uracil under conditions of a thermal model of prebiological chemistry. Science. 1961;133:1923-4.

Fry I. Emergence of life on earth: a historical and scientific overview. New Brunswick, NJ: Rutgers University Press; 2000.

Fuller WD, Sanchez RA, et al. Studies in prebiotic synthesis: VII. Solid-state synthesis of purine nucleosides. J Mol Evol. 1972;1 (3):249-57.

Gabel NW, Ponnamperuma C. Model for origin of monosaccharides. Nature. 1967;216(5114):453-5.

Gesteland RF, Atkins JF. The RNA world: the nature of modern RNA suggests a prebiotic RNA world. Cold Spring Harbor: Cold Spring Harbor Laboratory Press; 1993.

Gibson Jr EK. Volatiles in interplanetary dust particles: a review. J Geophys Res. 1992;97(E3):3865-75. 
Gibson DG, Benders GA, et al. Complete chemical synthesis, assembly, and cloning of a Mycoplasma genitalium genome. Science. 2008;319(5867):1215-20.

Glavin DP, Dworkin JP. Enrichment of the amino acid L-isovaline by aqueous alteration on CI and CM meteorite parent bodies. Proc Natl Acad Sci USA. 2009;106(14):5487-92.

Gupta RS. The natural evolutionary relationships among prokaryotes. Crit Rev Microbiol. 2000;26(2):111-31.

Haldane JBS. The origin of life. Rationalist Annual. 1929;148:3-10.

Hanczyc MM. The early history of protocells: the search for the recipe of life. In: Steen Rasmussen MAB, Chen L, Deamer D, Packard NH, Krakauer DC, Stadler PF, editors. Protocells: bridging nonliving and living matter. Boston: MIT Press; 2008.

Hargreaves WR, Mulvihill SJ, et al. Synthesis of phospholipids and membranes in prebiotic conditions. Nature. 1977;266(5597):7880 .

Hatzes APC, William D, Endl M, McArthur B, Paulson DB, Walker GAH, et al. A planetary companion to $\gamma$ Cephei A. Astrophys J. 2003;599(2):1383-94.

Hazen RM, Papineau D, et al. Mineral evolution. Am Mineral. 2008;93 (11-12):1693-720

Holland HD. Model for the evolution of the earth's atmosphere. In: Engel AE, James HL, Leonard BF, editors. Petrologic studies: a volume in honor of A.F. Buddington. New York: The Geological Society of America; 1962.

Holm NG, Andersson E. Hydrothermal systems. In: Brack A, editor. The molecular origins of life: assembling the pieces of the puzzle. Cambridge: Cambridge University Press; 1998.

Huber C, Wachtershauser G. Peptides by activation of amino acids with $\mathrm{CO}$ on $(\mathrm{Ni}, \mathrm{Fe}) \mathrm{S}$ surfaces: implications for the origin of life. Science. 1998;281(5377):670-2.

Ingar A-A, Luke RWA, et al. Synthesis of cytidine ribonucleotides by stepwise assembly of the heterocycle on a sugar phosphate. ChemBioChem. 2003;4(6):504-7.

Joyce GF, Schwartz AW, et al. The case for an ancestral genetic system involving simple analogues of the nucleotides. Proc Natl Acad Sci USA. 1987;84(13):4398-402.

Kasting JF, Siefert JL. Life and the evolution of Earth's atmosphere. Science. 2002;296(5570):1066-8.

Keefe AD, Miller SL. Are polyphosphates or phosphate esters prebiotic reagents? J Mol Evol. 1995;41(6):693-702.

Keefe AD, Newton GL, et al. A possible prebiotic synthesis of pantetheine, a precursor to coenzyme A. Nature. 1995;373 (6516):683-5.

Kempe S, Degens ET. An early soda ocean? Chem Geol. 1985;53(12):95-108.

Khare BN, Sagan C, et al. Amino acids derived from Titan tholins. Icarus. 1986;68(1):176-84.

Kuhn WR, Atreya SK. Ammonia photolysis and the greenhouse effect in the primordial atmosphere of the earth. Icarus. 1979;37(1):20713.

Lahav N, Chang S. The possible role of solid surface area in condensation reactions during chemical evolution: reevaluation. J Mol Evol. 1976;8(4):357-80.

Larralde R, Robertson MP, et al. Rates of decomposition of ribose and other sugars: implications for chemical evolution. Proc Natl Acad Sci USA. 1995;92(18):8158-60.

Laughlin G. A dance of extrasolar planets. Science. 2010;330 (6000):47-8.

Lauretta DS, McSween HY. Meteorites and the early solar system II. Tucson, University of Arizona Press; In collaboration with Lunar and Planetary Institute; 2006.

Lazcano A, Bada JL. The 1953 Stanley L. Miller experiment: fifty years of prebiotic organic chemistry. Orig Life Evol Biosph. 2003;33(3):235-42.
Lazcano A, Miller SL. How long did it take for life to begin and evolve to cyanobacteria? J Mol Evol. 1994;39(6):546-54.

Levy M, Miller SL. The stability of the RNA bases: implications for the origin of life. Proc Natl Acad Sci USA. 1998;95(14):7933-8.

Levy M, Miller SL, Oró J. Production of guanine from NH4CN polymerizations. J Mol Evol. 1999;49(2):165-8.

Levy M, Miller SL, et al. Prebiotic synthesis of adenine and amino acids under Europa-like conditions. Icarus. 2000;145(2):609-13.

Lincoln TA, Joyce GF. Self-sustained replication of an RNA enzyme. Science. 2009;323(5918):1229-32.

Löb W. Über das Verhalten des Formamids unter der Wirkung der stillen Entlandung. Ein Beitrag zur Frage der StickstoffAssimilation. Ber Dtsch Chem Ges. 1913;46:684-97.

Lodders K. Atmospheric chemistry of the gas giant planets. Geochem News 2010;142.

Lohrmann R, Orgel LE. Prebiotic synthesis: phosphorylation in aqueous solution. Science. 1968;161(836):64-6.

Lohrmann R, Orgel LE. Urea-inorganic phosphate mixtures as prebiotic phosphorylating agents. Science. 1971;171(970):490-4.

Love SG, Brownlee DE. A direct measurement of the terrestrial mass accretion rate of cosmic dust. Science. 1993;262(5133):550-3.

Maden BEH. No soup for starters? Autotrophy and the origins of metabolism. Trends Biochem Sci. 1995;20(9):337-41.

Manga M, Wang CY. Pressurized oceans and the eruption of liquid water on Europa and Enceladus. Geophys Res Lett. 2007;34(7): L07202.

Marshall-Bowman K, Ohara S, et al. Catalytic peptide hydrolysis by mineral surface: implications for prebiotic chemistry. Geochim Cosmochim Acta. 2010;74(20):5852-61.

Martin W, Baross J, et al. Hydrothermal vents and the origin of life. Nat Rev Microbiol. 2008;6(11):805-14.

Martins Z, Alexander CMO, et al. Indigenous amino acids in primitive CR meteorites. Meteorit Planet Sci. 2007;42(12):2125-36.

Matsumoto T, Yamamoto H, et al. Selective formation of triose from formaldehyde catalyzed by thiazolium salt. J Am Chem Soc. 1984;106(17):4829-32.

Maurette M. Micrometeorites on the early Earth. In: Brack A, editor. The molecular origins of life: assembling pieces of the puzzle. Cambridge: Cambridge University Press; 1998.

McCollom TM, Ritter G, et al. Lipid synthesis under hydrothermal conditions by Fischer-Tropsch-type reactions. Orig Life Evol Biosph. 1999;29(2):153-66.

McCollom TM, Lollar BS, et al. The influence of carbon source on abiotic organic synthesis and carbon isotope fractionation under hydrothermal conditions. Geochim Cosmochim Acta. 2010;74 (9):2717-40

Meier R, Owen TC, et al. A determination of the $\mathrm{HDO} / \mathrm{H} 2 \mathrm{O}$ ratio in comet C/1995 O1 (Hale-Bopp). Science. 1998;279(5352):842-4.

Miller SL. A production of amino acids under possible primitive earth conditions. Science. 1953;117(3046):528-9.

Miller SL. Production of some organic compounds under possible primitive earth conditions. J Am Chem Soc. 1955;77(9):2351-61.

Miller SL. The mechanism of synthesis of amino acids by electric discharges. Biochim Biophys Acta. 1957;23(3):480-9.

Miller SL. The endogenous synthesis of organic compounds. In: Brack A, editor. The molecular origins of life: assembling pieces of the puzzle. Cambridge: Cambridge University Press; 1998.

Miller SL, Orgel LE. The origins of life on the earth. Englewood Cliffs: Prentice-Hall; 1974.

Miyakawa S, Cleaves HJ, et al. The cold origin of life: B. Implications based on pyrimidines and purines produced from frozen ammonium cyanide solutions. Orig Life Evol Biosph. 2002a;32(3):209-18.

Miyakawa S, Cleaves HJ, et al. The cold origin of life: A. Implications based on the hydrolytic stabilities of hydrogen cyanide and formamide. Orig Life Evol Biosph. 2002b;32(3):195-208. 
Mojzsis SJ, Arrhenius G, et al. Evidence for life on Earth before 3,800 million years ago. Nature. 1996;384(6604):55-9.

Montmerle T, Augereau J-C, et al. 3. Solar system formation and early evolution: the first 100 million years. Earth Moon Planet. 2006;98 (1):39-95.

Morowitz HJ. Energy flow in biology. Woodbridge: Ox Bow Press; 1979.

Morse JW, Mackenzie FT. Hadean ocean carbonate geochemistry. Aquat Geochem. 1998;4(3):301-19.

Mukhin LM, Gerasimov MV, et al. Origin of precursors of organic molecules during evaporation of meteorites and mafic terrestrial rocks. Nature. 1989;340(6228):46-8.

Nelsestuen GL. Origin of life: consideration of alternatives to proteins and nucleic acids. J Mol Evol. 1980;15(1):59-72.

Nelson KE, Levy M, et al. Peptide nucleic acids rather than RNA may have been the first genetic molecule. Proc Natl Acad Sci USA. 2000;97(8):3868-71.

Nielsen PE, Egholm M, et al. Peptide nucleic acid (PNA). A DNA mimic with a peptide backbone. Bioconjug Chem. 1994;5(1):3-7.

Oparin AI. The origin of life. Moscow: Izd. Moskovshii Rabochii; 1924.

Orgel LE. Evolution of the genetic apparatus. J Mol Biol. 1968;38 (3):381-93.

Oró J. Comets and the formation of biochemical compounds on the primitive Earth. Nature. 1961;190(4774):389-90.

Oró J. Stages and mechanisms of prebiological organic synthesis. In: Fox SW, editor. The origin of prebiological systems and their molecular matrices. New York: Academic Press; 1965.

Oró J, Kimball AP. Synthesis of purines under possible primitive earth conditions. I. Adenine from hydrogen cyanide. Arch Biochem Biophys. 1961;94:217-27.

Oró J, Holzer G, et al. The contribution of cometary volatiles to the primitive Earth. Life Sci Space Res. 1980;18:67-82.

Osterberg R, Orgel LE. Polyphosphate and trimetaphosphate formation under potentially prebiotic conditions. J Mol Evol. 1972;1 (3):241-8.

Ourisson G, Nakatani Y. The terpenoid theory of the origin of cellular life: the evolution of terpenoids to cholesterol. Chem Biol. 1994;1 (1):11-23.

Pace NR. A molecular view of microbial diversity and the biosphere. Science. 1997;276(5313):734-40.

Peltzer ET, Bada JL, et al. The chemical conditions on the parent body of the Murchison meteorite: some conclusions based on amino, hydroxy and dicarboxylic acids. Adv Space Res. 1984;4(12):6974.

Pizzarello S, Cronin JR. Non-racemic amino acids in the Murray and Murchison meteorites. Geochim Cosmochim Acta. 2000;64 (2):329-38.

Pizzarello S, Cooper GW, et al. The nature and distribution of the organic material in carbonaceous chondrites and interplanetary dust particles. In: Lauretta DS, McSween HY, editors. Meteorites and the early solar system II. Tucson, University of Arizona Press; In collaboration with Lunar and Planetary Institute; 2006. p. 625-51.

Powner MW, Sutherland JD. Potentially prebiotic synthesis of pyrimidine beta-D-ribonucleotides by photoanomerization/hydrolysis of alpha-D-cytidine-2'-phosphate. ChemBioChem. 2008;9 (15):2386-7.

Powner MW, Anastasi C, et al. On the prebiotic synthesis of ribonucleotides: photoanomerisation of cytosine nucleosides and nucleotides revisited. ChemBioChem. 2007;8(10):1170-9.

Powner MW, Sutherland JD, et al. Chemoselective multicomponent one-pot assembly of purine precursors in water. J Am Chem Soc. 2010;132(46):16677-88.

Prieur BE. Étude de l'activité prébiotique potentielle de l'acide borique. C R Acad Sci-IIC-Chem. 2001;4(8-9):667-70.
Rabinowitz J, Hampai A. Influence of imidazole and hydrocyanic acid derivatives on the 'possible prebiotic' polyphosphate induced peptide synthesis in aqueous solution. Helv Chim Acta. 1978;61 (5):1842-7.

Reid C, Orgel LE. Synthesis in sugars in potentially prebiotic conditions. Nature. 1967;216(5114):455.

Rennó NO, Bos BJ, et al. Possible physical and thermodynamical evidence for liquid water at the Phoenix landing site. J Geophys Res. 2009;114(E1):E00E03.

Ricardo A, Carrigan MA, et al. Borate minerals stabilize ribose. Science. 2004;303(5655):196.

Robertson MMS. An efficient prebiotic synthesis of cytosine and uracil. Nature. 1995;375(6534):772-4.

Robertson MP, Levy M, et al. Prebiotic synthesis of diaminopyrimidine and thiocytosine. J Mol Evol. 1996;43(6):543-50.

Rubey WW. Geologic history of sea water. Geol Soc Am Bull. 1951;62 (9):1111-48.

Saladino R, Crestini C, et al. Formamide chemistry and the origin of informational polymers. Chem Biodivers. 2007;4(4):694-720.

Sanchez RA, Orgel LE. Studies in prebiotic synthesis. V. Synthesis and photoanomerization of pyrimidine nucleosides. J Mol Biol. 1970;47(3):531-43.

Sanchez R, Ferris J, et al. Conditions for purine synthesis: did prebiotic synthesis occur at low temperatures? Science. 1966a;153(731):72-3.

Sanchez RA, Ferris JP, et al. Cyanoacetylene in prebiotic synthesis. Science. 1966b;154(750):784-5.

Sanchez RA, Ferris JP, et al. Studies in prebiotic synthesis. II. Synthesis of purine precursors and amino acids from aqueous hydrogen cyanide. J Mol Biol. 1967;30(2):223-53.

Sanchez RA, Ferris JP, et al. Studies in prebiotic synthesis. IV. Conversion of 4-aminoimidazole-5-carbonitrile derivatives to purines. J Mol Biol. 1968;38(1):121-8.

Schlesinger G, Miller SL. Equilibrium and kinetics of glyconitrile formation in aqueous solution. J Am Chem Soc. 1973;9(5):3729.

Schmitt-Kopplin P, Gabelica Z, et al. High molecular diversity of extraterrestrial organic matter in Murchison meteorite revealed 40 years after its fall. Proc Natl Acad Sci USA. 2010;107 (7):2763-8.

Schopf JW. Microfossils of the Early Archean Apex chert: new evidence of the antiquity of life. Science. 1993;260(5108):640-6.

Schwartz AW. Specific phosphorylation of the 2[prime or minute]- and 3 [prime or minute]-positions in ribonucleosides. J Chem Soc D Chem Commun. 1969;23:1393a.

Schwartz AW, Chittenden GJ. Synthesis of uracil and thymine under simulated prebiotic conditions. Biosystems. 1977;9(2-3):87-92.

Schwartz AW, Degraaf RM. The prebiotic synthesis of carbohydrates —a reassessment. J Mol Evol. 1993;36(2):101-6.

Schwartz AW, Goverde M. Acceleration of HCN oligomerization by formaldehyde and related compounds: implications for prebiotic syntheses. J Mol Evol. 1982;18(5):351-3.

Shapiro R. The improbability of prebiotic nucleic acid synthesis. Orig Life. 1984;14(1-4):565-70.

Sowerby SJ, Mörth C-M, et al. Effect of temperature on the adsorption of adenine. Astrobiology. 2001;1(4):481-7.

Stoks PG, Schwartz AW. Uracil in carbonaceous meteorites. Nature. 1979;282(5740):709-10.

Stribling R, Miller SL. Energy yields for hydrogen cyanide and formaldehyde syntheses: the HCN and amino acid concentrations in the primitive ocean. Orig Life Evol Biosph. 1987;17(3-4):261-73.

Thomas PJ, Chyba C, et al., editors. Comets and the origin and evolution of life. New York: Springer; 1996.

Tian F, Toon OB, et al. A Hydrogen-rich early earth atmosphere. Science. 2005;308(5724):1014-7.

Tohidi M, Orgel LE. Some acyclic analogues of nucleotides and their template-directed reactions. J Mol Evol. 1989;28:367-73. 
Urey HC. The planets, their origin and development. New Haven: Yale University Press; 1952.

Urey HC, Cholnoky BJ, et al. Identity of organized elements. Ann N Y Acad Sci. 1963;108(2):606-15.

Vallentyne JR. Biogeochemistry of organic matter-II thermal reaction kinetics and transformation products of amino compounds. Geochim Cosmochim Acta. 1964;28(2):157-88.

Valley JW, Peck WH, et al. A cool early Earth. Geology. 2002;30 (4):351-4.

Voet $\mathrm{AB}$, Schwartz $\mathrm{AW}$. Uracil synthesis via $\mathrm{HCN}$ oligomerization. Orig Life. 1982;12(1):45-9.

Voet AB, Schwartz AW. Prebiotic adenine synthesis from $\mathrm{HCN}-$ evidence for a newly discovered major pathway. Bioorg Chem. 1983;12(1):8-17.

Wächtershäuser G. Before enzymes and templates: theory of surface metabolism. Microbiol Rev. 1988;52:452-84.

Wächtershäuser G. Groundworks for an evolutionary biochemistry - the iron sulfur world. Prog Biophys Mol Biol. 1992;58(2):85-201.

Waite Jr JH, Young DT, et al. The process of tholin formation in Titan's upper atmosphere. Science. 2007;316(5826):870-5.

Wang MY, Liudmila S, Caetano-Anollés D, Mittenthal JE, CaetanoAnollés G. Reductive evolution of architectural repertoires in proteomes and the birth of the tripartite world. Genome Res. 2007;17(11):1572-85.
Watson JD, Crick FHC. Molecular structure of nucleic acids: a structure for deoxyribose nucleic acid. Nature. 1953;171(4356):737-8.

White RH. Hydrolytic stability of biomolecules at high temperatures and its implication for life at 250 [deg]C. Nature. 1984;310 (5976):430-2.

Whittaker RH. New concepts of kingdoms of organisms. Science. 1969;163(3863):150-60.

Wochner A, Attwater J, et al. Ribozyme-catalyzed transcription of an active ribozyme. Science. 2011;332(6026):209-12.

Woese CR. The fundamental nature of the genetic code: prebiotic interactions between polynucleotides and polyamino acids or their derivatives. Proc Natl Acad Sci USA. 1968;59(1):110-7.

Woese CR, Kandler O, et al. Towards a natural system of organisms: proposal for the domains Archaea, Bacteria, and Eucarya. Proc Natl Acad Sci. 1990;87(12):4576-9.

Wolman Y, Haverland WJ, et al. Nonprotein amino acids from spark discharges and their comparison with the Murchison meteorite amino acids. Proc Natl Acad Sci USA. 1972; 69(4):809-11.

Yamagata Y, Watanabe H, et al. Volcanic production of polyphosphates and its relevance to prebiotic evolution. Nature. 1991; 352(6335):516-9.

Yuen GU, Kvenvolden KA. Monocarboxylic acids in Murray and Murchison carbonaceous meteorites. Nature. 1973;246(5431):301-3. 